\title{
DEPARTAMENTO CIENTIFICO
}

\section{CONGRESSO MEDICO-ESTUDANTINO \\ $\mathrm{DE}$ \\ S. PAULO}

Setemibro 1941

SESSÕES DE

ANATOMIA - QUIMICA FISIOLOGICA — PARASITOLOGIA - HISTOLOGIA - EMBRIOLOGIA - FISIOLOGIA - MICROBIOLOGIA - FARMACOLOGIA - ANATOMIA PATOLOGICA - TECNICA CIRURGICA - FISICA BIOLOGICA CLINICA MEDICA - CLINICA CIRURGICA DERMATOLOGIA - OTO-RINO - LARINCOLOGIA - UROLOGIA - HIGIENE - MEDICINA LEGAL - TERAPEUTICA - CLINICA - OFTALMOLOGIA - OBSTETRICIA - PEDIATRIA GINECOLOGIA - NEUROLOGIA - PSIQUIATRIA - ORTOPEDIA - HISTORIA DA MEDICINA. 


\title{
TRATAMENTO CIRÚRGICO DAS AFECÇÕES ARTERIAIS
}

\author{
DRS. EDGARD PINTO DE SOUZA A GABRIEL BOTELHO \\ DEPARTAMENTO DE TÉCNICA CIRÚRGICA E CIRURGIA EXPERIMENTAL \\ Diretor: PROF. E. VASCONCELOS
}

Em trabalho anterior, tivemos ocasião de estudar os conceitos gerais sôbre a patologia vascular; abordaremos, no presente, o assunto não menos interessante da patologia cirúrgica e tratamento de algumas das afecções arteriais.

$\left.1 .^{\circ}\right)$ Contusão arterial;

$\left.2 .^{\circ}\right)$ Ruturas e esmagamentos;

3. ${ }^{\circ}$ Feridas ;

4. $\left.{ }^{\circ}\right)$ Embolias;

$\left.5 .^{\circ}\right)$ Angiomas;

$\left.6 .^{\circ}\right)$ Aneurismas;

7. ${ }^{\circ}$ ) Arterite senil e trombo-angeite obliterante.

1..$^{\circ}$ Contusão arterial - Caracteriza-se anatomicamente pela existência de uma lesão da túnica interna, que expõe quasi que fatalmente à trombose e aos graves acidentes de obliteração arterial e embolia secundária com gangrena mais ou menos localizada. Nestas condições, o seu diagnóstico comporta uma indicação operatória formal e imediata. A verificação de um esfriamento periférico com desaparécimento do pulso, insensibilidade e paresia, após um traumatismo aberto ou fechado sôbre o trajéto de uma grande artéria, exige a descoberta, o mais precocemente possível, da mesmo. Surge, porém, uma dificuldade: pode haver somente uma contusão simpática periarterial, sem lesão do endotélio, portanto, sem o perigo da trombose. Em tal eventualidade, após algumas horas, cessam todos os fenômenos. $\mathrm{Na}$ prática diária, a conduta mais acertada vem a ser a seguinte: esperar de cinco a seis horas; se os sintomas se atenuam e o membro se aquece, é sinal que houve somente lesão da adventícia; se as perturbações se agravam, é que houve contusão arterial verdadeira, inpondo-șe, então, a intervenção cirúrgica imediata. 
De acôrdo com a sua gravidade, a contusão arterial pode apresentar três graus:

1. $\left.{ }^{\circ}\right)$ Atingir só a íntima ;

2. ${ }^{\circ}$ Atingir a íntima e a muscular;

3..$^{\circ}$ Atingir as três camadas.

No primeiro caso, não é indicado o tratamento imediato; o paciente deverá ficar em observação rigorosa, e aquele, instituído assim que surjam os primeiros sinais de trombose secundária.

Tratamento - Arteriectomia; o tratamento indicado é a resecção arterial, feita em tecido são, com ligadura das duas extremidades. A arteriotomia para a retirada exclusiva do trombo, seguida de sutura arterial, não dá resultado devido à lesão do endotélio; a recidiva da trombose seria, na maioria dos casos, a regra.

2..$^{\circ}$ Ruturas e esmagamentos - As ruturas podem ser espontâneas e traumáticas. As primeiras são as que se verificam nas artérias doentes, principalmente as atingidas pela sífilis. Exigem tratamento igual ao das ruturas traumáticas e mais a medicação específica. A's ruturas arteriais traumáticas são consequentes à lesão externa ou a manóbras cirúrgicas (redução de luxação e de fraturas). Distinguem-se dois tipos de ruturas:

a) Incompleta - Ha rutıra só da túnica interna; a consequência é a trombose progressiva, mais ou menos rápida, seguida de gangrena periférica.

b) Completa - Tôdas as camadas se rompem, forma-se um hematoma. Qualquer, porém, que seja o grau de lesão, a terminação é a gangrena periférica por isquemia, embolia ou compressão: A intervenção cirúrgica imediata impõe-se em todos os casos, desde que, naturalmente, não haja dúvidas no diagnóstico.

Tratamento - Como já sabemos, o trombo ou o coágulo, aquí, nada representam; a lesão da parede é tudo. É éla que precisa ser suprimida. A arteriectomia é uma necessidade. Como o foco é traumático, e não raro infectado, a reconstituição da artéria por sutura circular término-terminal não dá resultado. Nos casos favoráveis (lesão arterial muito limitada e integridade dos músculos adjacentes), ela poderá ser tentada. Nos casos mais antigos, apresentando já um processo de gangrena mais ou menos extensa, só a amputação resolverá o caso.

$\left.3^{\circ}\right)$ Feridas - Os ferimentos arteriais vêm, como causa coadjuvante à sua frequência, a relativa fixidez das artérias e a sua vizinhança com os pontos ósseos.

Os ferimentos arteriais podem ser classificados em:

a) Penetrantes, quando a luz do vaso é aberta.

b) Não penetrantes, quando somente uma ou as duas túnicas externas são lesadas.

c) Perfurantes, quando a parede vasal é atravessada em dois pontos. 
Os ferimentos arteriais podem, ainda, ser completos e incompletos.

É completo quando interrompe a continuidade do vaso e incompleto quando somente uma parte da circunferência é lesada.

Os ferimentos arteriais em geral, podem apresentar complicaçõos imediatas e tardias: como consequência imediata de maior monta, temos a hemorragia, que poderá levar à morte ou à formação de hematoma. A consequência tardia ou é uma trombóse ou um aneurisma ou ainda um hematoma pulsátil organizado e a gangrena.

Tratamento - O problema do tratamento das feridas arteriais (córte, laceração e perfuração) completas e incompletas, se apresenta com condições clínicas muito diversas. De uma maneira geral, tôda ferida arterial diagnosticada deve ser operada o mais cêdo possível; da mesma maneira, tôda ferida penetrante, por mínima que seja, interessando uma região, por onde, normalmente, passam vasos importantes, exige uma exploração cirúrgica do feixe vascular tão precoce quanto possível. Tal conduta é justificável pelo fato de poder-se verificar uma ferida arterial sem sanǵramento. A vaso-constricção e a formação rápida do coágulo obliterante impedem a saída do sangue; porem, logo cessada aquela, ou mesmo tardiamente, dar-se-á a eclosão da ferida arterial, com hemorragia que poderá levar o indivíduo à morte. Por outro lado, mesmo que não haja hemorragia secundária, pode-se desenvolver, posteriormente, no vaso lesado, um anuerisma, com as suas consequências: trombose e daí embolia e gangrena.

Tratamento: 1) Combater a hemorragia: transfusão, soro gomado, soros isotônicos, cardiotônicos, veritol, etc.

2) Intervenção cirúrgica: o objetivo da operação é variáve!:

a) nos ferimentos arteriais acidentais, para fazer a hemostasia, prevenir a formação de um hematoma enquistado e, ulteriormente, de um aneurisma, todos os dois perigosos para a circulação periférica.

b) Nas feridas sêcas, isto é, onde não se verifica hemorragia, prevenir a hemorragia secundária e reparar as lesões.

c) Nos hematomas difusos, fazer a hemostasia, prevenir a gangrena por isquemia e a gangrena por infecão (gangrena gasosa).

d) Nos hematomas enquistados, reparar a lesão arterial e impedir a formação de um aneurisma.

Quanto aos prócessos cirúrgicos em si, constam êlés da arteriectomia e da sutura arterial; a primeira leva sempre a preferência ; fazse a ligadura dos dois extremos e resseca-se o segmento arterial interessado. A sutura fica reservada para certos casos escolhidos, como

4..$^{\circ}$ Embolias - $\mathrm{Na}$ embolia arterial, tanto a patogenia como o tratamento implicam sempre na consideração de dois fatores fundamentais: a embolia em si e a causa determinante da mesma, que na quasi totalidade dos casos é uma endocardite.

As embolias arteriais têm a particularidade de se verificarem de preferência nos lugares de bifurcação dos vasos (terminação da aorta, 
bifurcação das iliacas, emergência da femural profunda etc); estendem-se, daí vagarosamente por trombose secundária ou coágulo prolongado, em direção periférica, atingindo os finos ramos arteriais.

Considerados a etiologia e o fato agudo em si, é ainda necessário levar em conta a séde da embolia, a sua evolução, e as complicações prováveis e as fatais.

O fator etiológico é de tão grande importância que JoÃo CID Santos avalia que $2 / 3$ dos casos de embolia são de origem endocárdica e apresentam uma evolução fatal dentro de um mês após a crise aguda, por repetição em outras localizações (cérebro, vísceras) ou ainda por insuficiência cardíaca.

Um de nós já teve oportunidade de diagnosticar e operar (embolectomia) um caso de embolia da artéria femural comum, por êmbolo encravado no ponto de emergência da femural profunda quatro horas antes. Tratava-se de um paciente do Serviço do Dr. Z. Amaral, que, após a embolectomia e arteriorrafia, mostrou aquecimento do membro em questão, com desaparecimento das dores.

O paciente cinco dias depois veiu a falecer subitamente. A autópsia demonstrou a existência de endocardite vegetante e de numerosos infartos, velhos e recentes, nos rins, no baço, e um enorme e recente infarto pulmonar que o levara à morte.

A parte os casos em que a embolia arterial assume certa autonomia, devido ao silêncio da moléstia de origem, os outros devem ser tratados cirurgicamente, excetuando-se aqueles em que há assistolia. Como consequência direta da embolia, produz-se um espasmo arterial, duradouro, visível mesmo à distância, originando-se uma tromböse secundária que evolue relativannente depressa em direção periférica e; ao fim de dias, é difícil dizer se a trombose foi primitiva ou secundária a um êmbolo.

Com a evolução progressiva da trombose secundária, verificamos que a maioria das obliterações dos troncos arteriais principais é seguida de gangrena, quando a circulação colateral é igualmente interrompida. Isto também se vê quando a interrupção é muito brusca, não dando tempo necessário para o desenvolvimento da circulação colateral. Quando esta se desenvolve de maneira satisfatória e eficiente, verificamos que a circulação do membro se restabelece, desaparecendo os sinais premonitores da gangrena.

São vários os fatores que intervêm no futuro de um segmento de membro, que viu a sua artéria principal obliterada por um êmbolo; um dos mais importantes é a trombose ocasionada pelo coágulo progressivo, trombose esta que se verifica nos dois sentidos do ponto de implantação, e que vai a pouco e pouco obstruindo os ramos colaterais que partiam do vaso, acima do ponto obstruido. E absolutamente impossível prever a extensão dêste coágulo e a sua velocidade de progressão.

Dos dados acima, concluímos que a intervenção nas embolias arteriais só poderá obter bons resultados quando for executada antes que se estabeleça a trombose progressiva, sobretudo a da circulação 
colateral. Como isto é uma questão de tempo e, portanto, imprevisível, só se pôde tirar conclusõoes após uma demorada experiência cirúrgica, e ela só assinala bons resultados quando a embolectomia é executada dentro das 10 a 12 primeiras horas após o acidente agudo.

Os resultados da cirúrgia vascular, inicialmente precários devido à trombose provocada pela arteriorrafia e manipulação das paredes arteriais, melhoraram nestes últimos anos, verificando-se, com relativa frequência, bons resultados nas mãos de certos cirurgiões, devido aos estudos e ao material de sutura recomendado por CARrel e MAtas.

A obstrução brusca da luz arterial produz dor intensa ao longo do membro, que se torna pálido e frio; êstes três sintomas não podem ser explicàdos somente pela obliteração.

Verifica-se, portanto, que desde o momento em que se deu a embolia instala-se uma complicação de ordem vaso-motora, puramente funcional. Em consequência disto, vemos o bloqueio regional atingindo os vasos colaterais e se estendendo à rede capilar.

Esta reação vaso-motora, que se segue à embolia, é extremamente variável com o indivídio e, de uma maneira geral, podemos dizer com Cid Santos que a embolia é revelada através dos fenômenos vaso-motores. A verificação dêste espasmo arterial predominando no quadro clínico, permite-nos compreender a patogenia do coágulo e do trombo progressivo que se segue à embolia e o tratamento proposto por Leriche pelo bloqueio do sistema simpático pela novocaina.

$\mathrm{Na}$ questão do diagnóstico da embolia arterial, além do exame geral '(dor, palidez, ausência de pulsação, antecedentes cardíacos e exame físico do coração), podemos lançar mão de dois excelentes meios que nos dirão da exata localização da obstrução arterial.'

Esta localização, aproximadamente, é feita pela oscilometria, que podená ou não ser confirmada pelo único processo realmente preciso, a arteriografia.

A arteriografia, além de nos dar com precisão a localização do êmbolo, nos díz sôbre o eștado da circulação colateral:

$\mathrm{Ha}$ ainda casos de sintomatologia indicando uma trombose arterial, en que a arteriografia mostra a permeabilidade perfeita da árvore arterial e a flebografia revela a existência de uma trombose venosa.

Do que expusemos acima sôbre os fenômenos relativos ao espasmo à distância iremos nos utilizar mais tarde, quando tratarmos da terapêutica dêste acdiente.

5..$^{\circ}$ Angiomas - Angioma ou hemangioma é um tumor, constituído por uma neoformação de vasos. Na prática corrente, é muitas vezes difícil dizer se uma coleção de vasos é um verdacleiro neoplasma ou se é uma mera dilatação de vasos pré-existentes, isto é, uma telangiectasia.

Distinguem-se duas fórmas de angiomas, o capilar e o cavernoso. Segundo a natureza do tecido conjuntivo em que está incluído o angioma, trata-se de um angiofibroma, de um angiolipoma etc. 
Pode-se verificar a degeneração maligna, desenvolvendo-se então ùm angiosarcoma. Dos angiomas o mais comumente encontrado é 0 chamado hemangioma simples; consta de uma mancha na pele, de côr vermelho-viva, em geral arredondada e de bordos nítidos. Desenvolve-se comumente na face, onde atinge, às vezes, grandes dimensões.

Tratamento - Extirpação do segmento de pele sôbre o qual se assenta o hemangioma, seguida de restabelecimento da solução de continuidade por meio de enxertos. Pode-se igualmente, tratá-los por punções repetidas com cautério, pela coagulação com neve carbônica, pela radiumterapia.

6.) Aneurismás - Aneurisma é a dilatação dè uma artéria: a dilatação venosa é chamada variz. Segundo a sua definição, a parede de todo aneurisma deve ser constituída pelas três túnicas arteriais, pois que o saco aneurismático é formado pela parede dilatada do vaso. "As variedades de aneurisma em que realmente assim ocorrem as cousas, chaman-se aneurismas verdadeiros. Sua gênese é muito variável: congênitos; por enfermidade das paredes vasculares

(artério-esclerose, sífilis, etc.) ; por perda da elasticidade da parede como consequência de uma contusão. Quando o traumatismo provoca somente a rutura da túnica interna, o sangue pode se difundir entre as camadas do vaso, formando o chamado aneurisma dissecante.

Para o cirurgião tem, porém, maior importância o chamado neurisma espúrio traumático, o qual se diferencia do aneurisma verdadeiro pela sua gênese. Um ferimento fechado penetrante na par rede da artéria, mas cujo sangue estravasado não se exterioriza, ou porque o ferimento é mesmo fechado ou porque os tecidos vizinhos o impedem, produz um hematoma que pode assumir proporções mais ou menos grandes. Esta coleção sanguínea se coagula na sua parte externa e os tecidos circundantes se organizam, formando-se um verdadeiro tecido cicatricial. O centro do hematoma sofre, em parte. uma liquefação e é reabsorvido, e, em parte, é escavado pela corrente sanguínea, de modo tal que se forma um saco, cujas paredes não são constituíclas como as do aneurisma verdadeiro, pelas paredes da artéria, nem são revestidas pela íntima, mas sim formadas por numerosos trombos em fórma de lojas (falso aneurisma).

Quando são lesadas, simultaneamente, uma artéria e uma veia, forma-se uma comunicação entre os dois vasos; estabelece-se, então, uma fístula ou um aneurisma artério-venoso. Em regra geral, a parede da veia por ser a mais débil, é a que cede, razão pela qual esta afecção é também conhecida pela denominação de variz aneurismática.

É aquí, com o aneurisma artério-venoso, que se notà o maior desenvolvimento da circulação colateral.

A figura 17 mostra, em esquema, os diferentes tipos de comunicação artério-venosa que, em regra geral, trazem grandes perturbações funcionais, como dores, fenômenos tróficos, paralisias, edemas, 
etc. O membro atingido torna-se inútil e doloroso; ha ainda o grande perigo das inflamações, da rutura e da embolia.

A figura 18 mostra o estado da perna de um rapaz portador de um aneurisma artério-venoso, localizado no $1 / 3$ médio da coxa, entre a artéria femural superficial e a veia femural, produzido por feri-
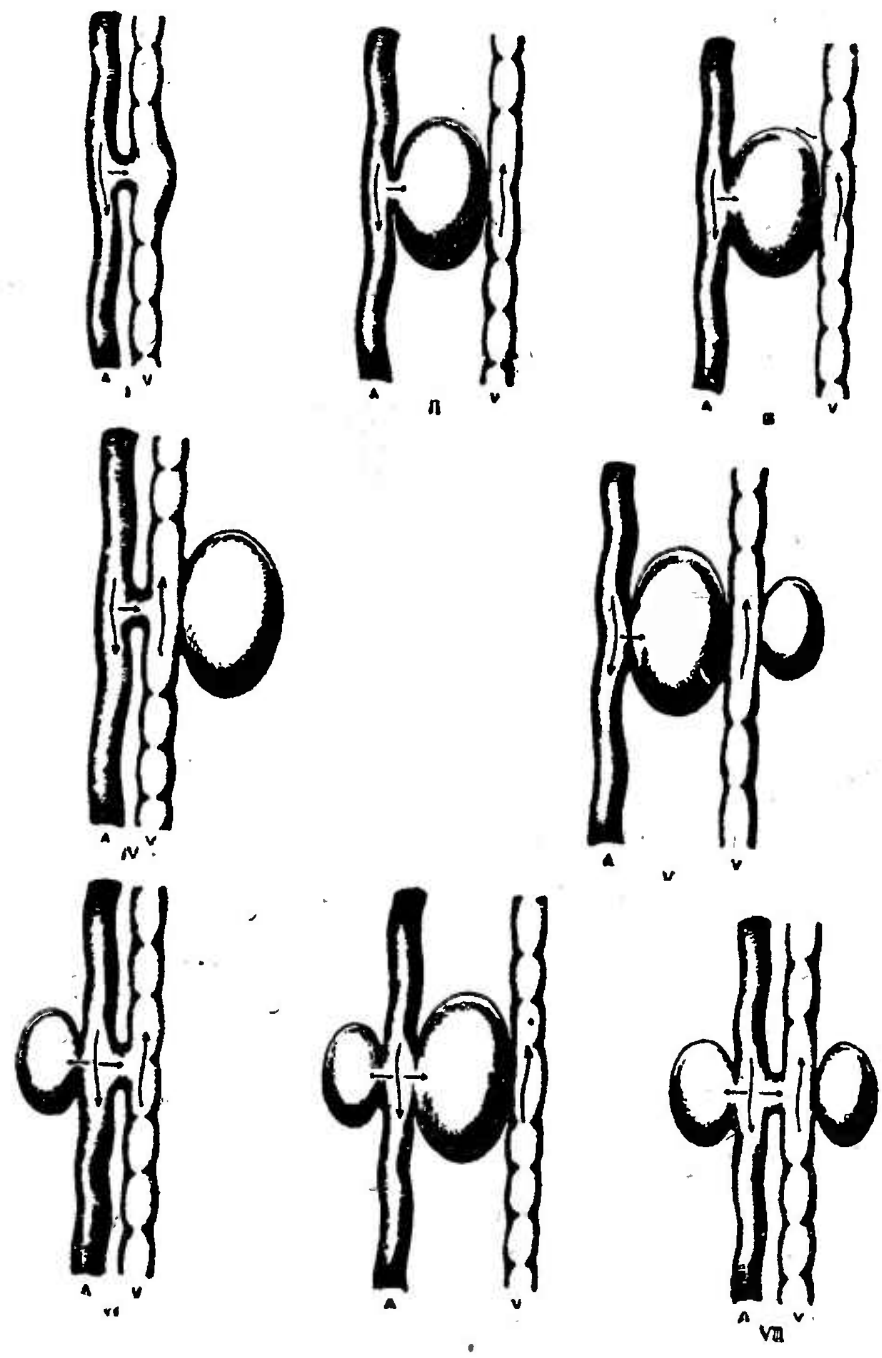

FIg. 17

Tipos de comunicações artério-venosas anormais. I - fístula artério-vienosa com comunicàção direta imediata; aneurisma varicoso. II - aneurisma artério-venoso com falso saco intermediário. III - aneurisma artério-venoso com saco arterial. Aneurisma varicoso secundário. IV - fístula artério-venosa com saco venoso. V - aneurisma artério-venoso com falso saco internediário e variz do outro lado da veia, devido à dupla lesão da última. VI - aneurisma artério-venoso com comunicação imediata (fístula) e saco no lado arterial. Lesão venosa simples $\epsilon$ arterial dupla. VII - aneurisma artério-venoso com falso saco intermediário e um aneurisma arterial devido a lesão venosa única e arterial dupla. VIII - fístula artério-venosa com sacos opostos dévido a lesão dupla de ambos os vasos. (in Reid e Andrus (Neison).

mento cortante (faca), dois anos antes. Note-se o acentuado aumento de volume da perna e as ulcerações tróficas. 
O aneurisma artério-venoso pode apresentar a seguinte etiologia: a) traumática, a mais frequente; b) espontânea; c) supurativa; d) congênita.

Os casos assinaladòs na literatura como de origem espontânea, são os da aorta, que'se abriram secundariamente na. veia cava su-

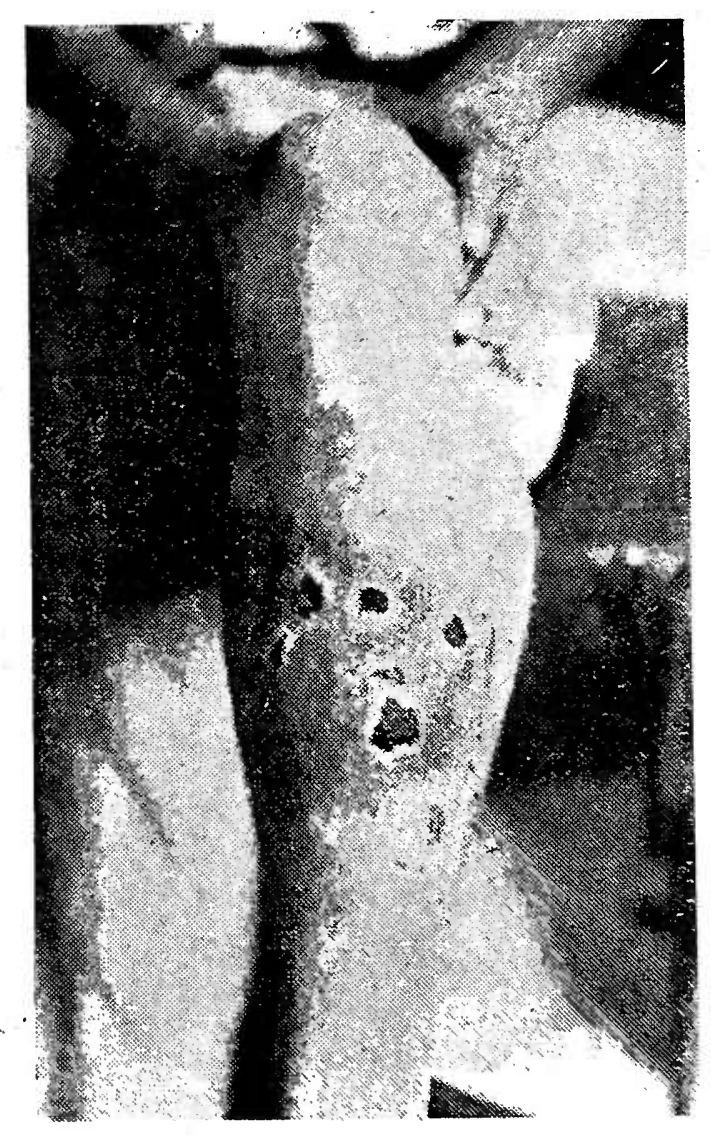

FIG. 18

Lesões trófıcas decorrentes de un aneurisma artério-venoso no $1 / 3$ médio da coxa.

perior ou na sub-clávia. Uma outra variedade de aneurisma artériovenoso é o cirsóide, que se verifica entre os vasos de pequeno calibre, podendo, aquí também, ser de origem traumática ou congênita.

Uma das consequências mais graves do aneurisma artério-venoso é a dilatação do coração, além de outras de não menor significação como o edema, lesões tróficas, paralisias musculares e hiperpigmentação abaixo do aneurisma.

Verificam-se, aquí, dois sistemas circulatórios periféricos: coração, artéria, capilar e leito venoso e coração, artéria, fístula e leito venoso, com sobrecarga do sistema venoso e, portanto, hipertensão.

Em virtude das suas graves consequências, conclue-se facilmente que se impõe o tratamento cirúrgico nesta afecção.

$\left.7 .^{\circ}\right)$ Arterites - E' uma questão muito complexa. Não somente devido ao polimorfismo, comio também por não se verificarem. com o mesmo aspecto e gravidade em todos os doentes e regiões. 
Ha, em relação às artérias dos membros, tromboses post-traumáticas, como já vimos, e raras arterites agudas localizadas, sobrevenientes às moléstias infecciosas.

A maioria das arterites obliterantes espontâneas são moléstias crônicas, que se manifestam algumas vezes de maneira brusca, mas que sempre têm início insidioso e são sempre de evolução lenta.

As arterites, apesar de muitas vezes darem a impressão de serem localizadas, após uma observação longa mostram outras localizações e devem ser consideradas como expressão de uma moléstia geral que pode atingir todo o sistema arterial.

\section{CLASSIFICAC̨ÃO DAS ARTERITES}

Com Leriche e Fontaine podemos dizer que, praticamente, há duas espécies de arterias espontâneas, a arterite senil ou artério-esclerótica e a juvenil ou trombo-angeite de Leo Buerger.

A sífilis não tem influência alguma em relação à arterite dos membros.

\section{HISTO-PATOLOGIA DAS ARTERITES}

Distinguem-se quatro fórmas histológicas de arterite.

$\left.1^{\circ}\right)$ A artério-esclerose, que se inicia por uma hipertrofia da. íntima e do tecido elástico, seguida de degeneração gordurosa, de es clerose e de calcificação.

$\left.2^{\circ}\right)$ A calcificação da túnica média, tipo Mönckeberg, caracterizada pela degeneração das fibras musculares e por uma distrofia hidro-gordurosa do tecido conjuntivo, com calcificação das placas degeneradas.

$\left.3 .^{\circ}\right)$ Arterites parietais com trombose, nas quais o tecido elástico desaparece e ha focos inflamatórios disseminados.

4. ${ }^{\circ}$ ) Pan-arterite de Buerger, com infiltrações leucocitárias e células gigantes.

Todos êstes tipos de arterite são acompanhados de lesões da endartéria, de espessamentos localizados, daí a designação genérica de endarterite obliterante. Exatamente sôbre estas placas de endarterite que se iniciam os processos de coagulação.

$\mathrm{Na}$ prática, no entanto, no exame das peças, é frequente ver associação, no mesmo córte, de lesões de artério-esclerose, de calcificações da média, com as células inflamatórias, células gigantes da trombo-angeite.

É devido a esta frequente associação de lesões histo-patológicas em peças deamputação por gangrena que LERICHE e. FonTAINE pensaram em abandonar o critério de classificação histológica das arterites, passando a classifica-los pelos dados da cirúrgia e pela arteriografia. 
Fontaine, com o auxílio da arteriografia com o torotrast, e seguindo a orientação, e o aparêlho preconizado por REYNALdo Santos, conseguiu evidenciar dois tipos bastante distintos de arterites, sob o ponto-de-vista da morfologia radiográfica.

Um primeiro tipo, no qual a arteriografia apresenta um desenho largo, irregular, flexuoso, a artéria, permeávél pelo menos parcialmente, é mais volumosa do que a normal. Esta imagem é confirmada pela operação e corresponde às arterites senis, à àrtério-esclerose $e$ às fórmas calcificadas da média.

Um segundo tipo, que é caracterizado pela rédução concêntrica do volume das artérias que se mostram regulares e retilíneas. Esta imagem dá a impressão de que as artérias se acham contraídas.

Esta imagem é visível mesmo nos membros superiores, e verifica-se que, mesmo nas zonas livres, à distância da obstrução, as artérias apresentam um calibre reduzido e sem flexuosidades.

Muitas vezes as artérias gástricas e a coronária são atingidas.

Esta imagem é própria da trombo-angeite obliterante e ela é evidentemente uma moléstia geral.

\section{ETIOLOGIA DAS ARTERITES}

Nada se sabe ainda de positivo a respeito da causa original das arterites.

A infecção já foi apontada como causa etiológica, mas as culturas, em diferentes meios, dos segmentos arteriais trombosados, não evidenciaram o desenvolvimento de colónias.

Na Itália, Maragliano e sua Escola, e, tempos depois, Froelich, da Escola de LERICHE, tentaram 'reproduzir experimentalmente a trombo-angeite obliterante em coelhos por meio de enxêrto de cápsula supra-renal.

Os AA. citados faziam enxertos homoplásticos de cápsula su-pra-renal, repetindo-os cada 4 dias, dada a sua pequena resistência à autólise que se processa rapidamente.

Os animais eram, assim, mantidos em um estado de hipersuprarrenalismo permanente e, ao fim de poucas semanas, as artérias apresentavàm uma diminuição geral do calibre. redução da luz, espessamento da parede com alterações da íntima, hipertrofia da média, degeneração da muscular e alteração da adventícia. As lesões obtidas são mais ou menos as mesmas, mas as condições de evolução são absolutamente diversas; na afecção do homem, as artérias vêm sendo manejadas pelo processo de longa data e as artérias são examinadas após anos de moléstia, ao passo que, na experimentação, as artérias são examinadas con algumas semanas de enxêrto.

A experimentação não reproduz de maneira idêntica a moléstia espontânea, tanto no tempo como na duração e nas reações inúmeras que acompanham o quadro clínico. 
No entanto, continuando a experimentação, os AA. observaram, nos animais enxertados, alterações da supra-renal, da hipófise e glândulas gênitaes, que se mostraram com hiperplasia e hipertrofia.

As lesões arteriais, semelhantes às vistas na trombo-angeite obliterante, também foram vistas por Pescatori e Bernabeo, da Escola de PAOLuccr, com injeções do hormônio para-tireoidiano. Além das lesões arteriais nos animais hipercalcêmicos, encontraram os AA. lesões da medula supra-renal.

Ora, no homem com hipercalcemia, já foi vista a existência de lesões da endartéria.

Os fatos assim concordantes parece quererem atribuir, tanto à trombo-angeite como à artério-esclerose, uma origem supra-renal.

Evolução - Qualquer que seja a etiologia das arterites, em um momento dado as artérias se acham trombosadas; isto quer dizer que agora a arterite se acha complicada

O mecanismo da trombose é já nosso conhecido por estudo anterior, de maneira que não iremos repisar êste particular. $O$ que ha de muito interessante a respeito da agravação da moléstia é que ela nem sempre se traduz e quando se manifesta o faz de diferentes maneiras.

Vemos, assim; que é muito frequente examinarmos indivíduos que apresentam queixas mínimas para o lado de um dos membros e o exame minucioso comparativo nos mostra a existência de trombose bilateral, enquanto é só de um dos lados que apresenta distúrbios vaso-motores. $\mathrm{Ha}$ ainda casos, e não raros, de trombose arteriais extensas e absolutamente mudas.

É evidente que existe, além do fator mecânico obstrutivo, um outro elemento que a êle se associa e que empresta à moléstia o seu caráter polimorfo.

Os estudos minuciosos de Leriche, que dedicou longos anos à sua interpretação, levaram-no a conclusões interessantíssimas: assim, verificou êle que, naqueles casos em que havia graves distúrbios vasomotores, o exame microscópico das artérias revelava um edema perivascular, esclerose, provocando quasi que uma sínfise entre artéria e veia, circulação anormal da parede, com os vasa vasorum dilatados; ao passo que, naqueles casos sem sintomas aparentes, a adventícia não era atingida.

Isto quer dizer que, quando o proceśso inflamatorio atinge a adventícia, ponto de partida de nervos centrípetos, o segmento de artéria obstruido passa a atuar não mais como artéria e sim como nervo, ponto de partida de reflexos, que iriam provocar, espasmos à distância.

Sob o ponto-de-vista de físio-patologia, é de muito maior importância o distúrbio ocasionado pela inervação parietal do que o próprio obstáculo à circulação sanguínea. 
A supressão da corrente sanguínea origina geralmente fenômenos localizados de isquemia, distúrbios parcelares por insuficiência circulatória, e, durante o período de atividade funcional, verifica-se a chamada claudicação intermitente.

Todos os outros fenômenos, que, em suma, constituem o quadro clínico da afecção, são derivados dos distúrbios da inèrvação parietal. São os reflexos partidos da parede que provocam as crises vaso-constrictoras, a estase, o ediema, a cianose, o resfriamento periférico e os. distúrbios tróficos.

A prova disto está na terapêutica; a simples ressecção do segmento arterial trombosado faz cessar todos os fenômenos, permanecendo somente a claudicação intermitente.

\section{EXPLORAC̨ÃO FUNCIONAL DAS ARTÉRIAS}

Sendo as perturbações funcionais, como vimos, de grande importância no quadro clínico e na evolução da moléstia, é fundamental que se faça um estudo funcional aprofundado para que se possa ajuizar da evolução da arterite.

O estudo do valor funcional das artérias periféricas tem um dup1o interêsse: diagnóstico e prognóstico. É êle que permite assegurar a presença, a extensão, a natureza das lesões e o estado da circulação de suplência, contribue para fixar o limite útil da terapêtutica conservadora funcional e determinar o limite da amputação.

Inúmeros são os processos descritos, mas, na realidade, dois deles somente dão uma noção exata das condições existentes e orientam o tratamento: a oscilometria e a arteriografia.

$A_{1}$ oscilometria, quando pesquisada meticulosa e comparativamente dos dois lados e em níveis muito próximos, dá informações sôbre a permeabilidade das artérias principais dos membros, não dando, no entanto, a menor informação sôbre o estado dos ramos secundários, das arteríolas e colaterais.

Com certa experiência da prática ocilométrica, o exame de uma curva permite, muitas vezes, fắzer o diagnóstico de uma afecção obstrutiva. Quando vemos, por exemplo, logo acima do nível obstruído, uma curva que se inicia muito cêdo entre 25 e 30 , cujo nível sobe regularmente e se mantém elevado durante um longo período formando um planalto elevado e só abaixo com pressões muito pequenas, quasi que se pode garantir tratar-se de um caso de artério-esclerose com artérias ainda permeáveis, mas com paredes rijas, que vibram intensamente com a onda pulsatil. (fig. 19)

Nos casos de sintomatologia dúbia entre endarterite e Moléstia de RAynaud, a curva oscilométrica ordinária não elucidando, é necessário praticá-la após os banhos de contraste. A curva é obtida, em primeiro lugar, à temperatura ambiente; em seguida, é o segmento de membro mergulhado em água entre $35 .^{\circ}$ e $37 .^{\circ}$, aí permanecendo 
10. minutos; após o enxugamento é feita nova curva. Mergulha-se, em seguida, em água fria a zero grau durante cinco minutos. Normalmente, a curva obtida à temperatura ambiente se mantém a igual distància entre as obtidas após o banho quente e o frio. $\mathrm{O}$ mesmo já se não verifica em relação à moléstia de RAYNAUd, onde vemos quasi que o desaparecimento completo do índice oscilométrico após o banho frio, traduzindo, com esta resposta, um exagêro da reação ao frio. Já nos casos de endarterite, muito pouca alteração se verifica; não ha oscilação à temperatura ambiente, ela se esboça com o calor e continua não surgindo após o banho frio. (figs. 20 e 21)

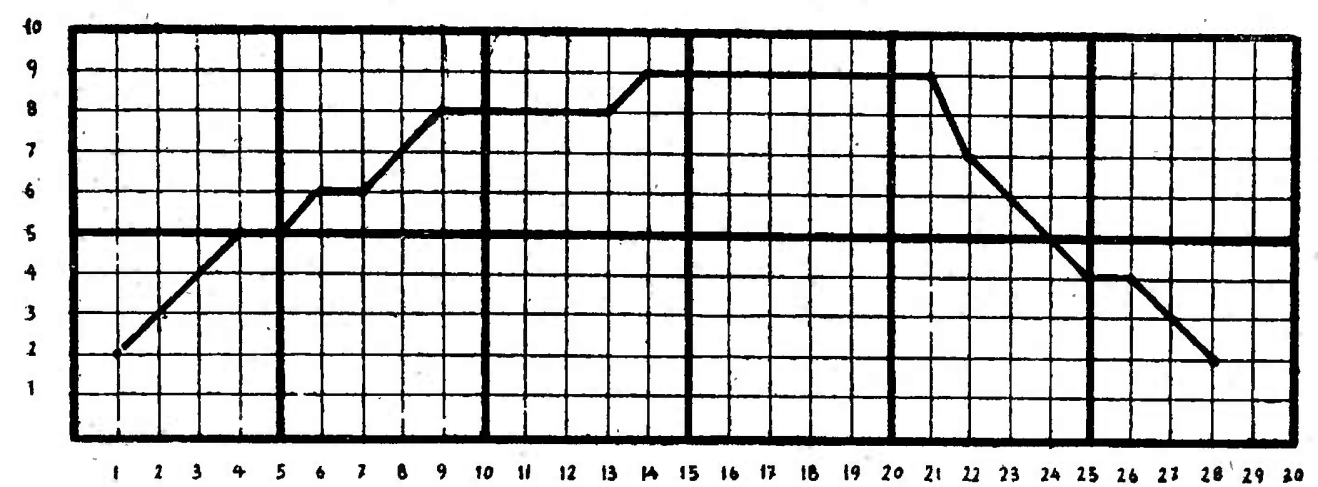

FrG. 19

Curva oscilométrica num caso de arterite senil.

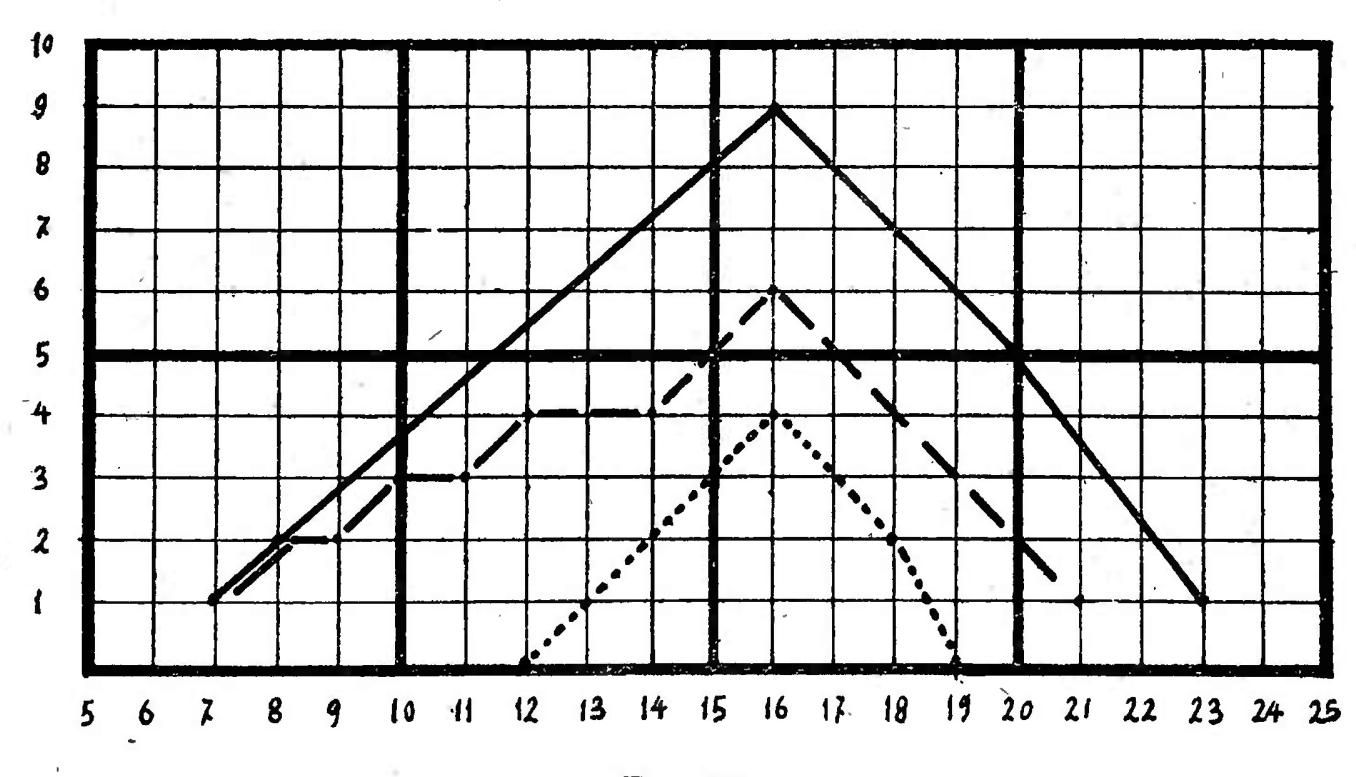

FIG. 20

Curvas oscilométricas de um indivíduo normal. Em traços interrompidos e pontos, índice ̀े temperatura ambiente. Em traços cheios, após banho quente. Em pontilhado, após banho frio. 


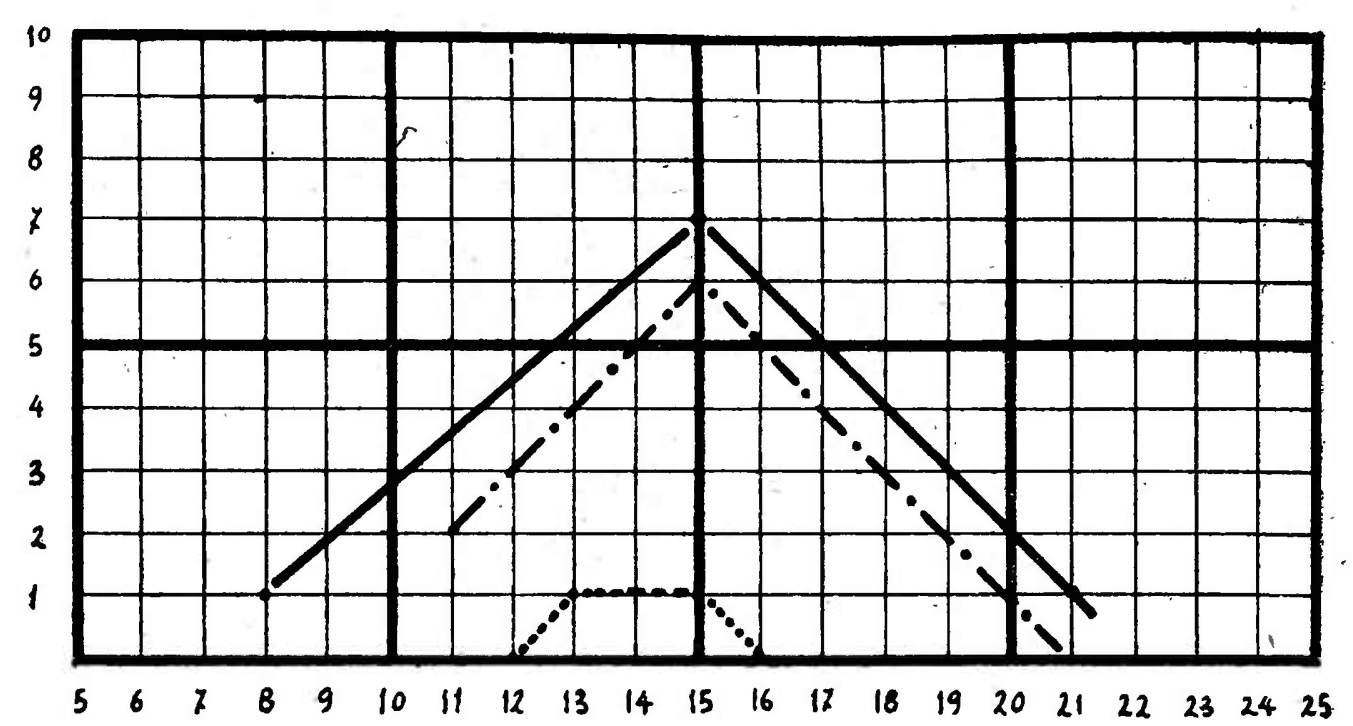

FIG. 21

Curvas oscilométricas no mal de Raynaud. Em traço $\epsilon$ ponto, curva obtida à temperatura ambiente. Em traços cheios, após banho quente. Em pontilhado, após banho frio. Exagero da reação ao frio.

\section{IMPORTÂNCIA DA CIRCULAC̣ÃO COLATERAL}

A obstrução arterial brusca ou lenta cria um regime circulatório absolutamente novo, que poderá conservar a integridade dos tecidos desde que se achem reunidos, na ocasião do acidente, três fatores:

a) tensão arterial suficiente a montante, querendo se dizèr com isto energia contrátil normal do miocárdio.

b) vaso-dilatação conveniente de tôda a rede arterial periférica. É necessário que ela seja o mais permeável possível. Desde que haja vaso-constricção, instala-se a insufiência circulatória e as veias colaterais se organizam mal.

c) um número suficiente de anastomoses entre os ramos arteriais. Esta última condição não se realizando, a gangrena do membro é dificilmente evitável, mesmo que as duas primeiras condições se achem presentes.

É somente a arteriografia que fornece ésclarecimentos sôbre o estado da circulação colateral.

A disposição que mais favorece a integridade dos tecidos é a verificadla quando existe uma anastomose entre dois ramos da mesma artéria, nascendo em níveis diferentes, verificando-se a trombose entre os clois. Vemos a corrente principal se restabelecer por enchimento, por via retrógrada, por intermédio da artéria colateral inferior.

O nível da obliteração e a sua extensão teem uma importância decisiva. A séde da trombose pode ser tal que o restabelecimento por via colateral seja impossivel. 
A experiência mostrou que o que condiciona o futuro de um trombosado é o enchimento por via colateral do tronco principal a jusante da obliteração.

É somente êste enchimento que permite uma distribuição sanguínea suficiente à jusante.

Se isto não se observar, na coxa por exemplo, por mais rica que: seja a rede anastomótica e colateral, ela não assegurará uma vascularização suficiente na perna e no pé. As anastomoses não franqueiam jamais as zonás de flexão e não são suficiẹtes por si sós para garantir a vitalidade periférica.

Uma arteriografia mostrando uma bôa circulação colateral na coxa, sem enchimento da poplitéia, indica a necessidade de uma amputação da coxa em tecidos bem irrigados. A cirurgia do simpático, aí, em nada adiantaria. Nos casos em que a poplitéia se enche bem, abaixo da obliteração, pode-se esperar que a supra-renalectomia, a simpactetomia lombar ou a arteriectomia deem resultado.

Disto se conclue a absoluta necessidade da arteriografia na cirurgia conservadora das arterites.

A arteriogrfia feita com o torotrast e com a ajuda do aparêlho de Reynaldo Santos é inócua e precisa.

\section{TERAPÊUTICA CIRÚRGICA}

À međida que fomos tratando das diferentes afecções, acenámos: ligeiramente sôbre a terapêutica respectiva e agora iremos tratar, com maior minúcia, das diferentes técnicas aplicáveis às várias afecções, segundo a sua gravidade, frisando aquela que julgarmos mais indicada, as suas vantagens e desvantagens.

1. $\left.{ }^{\circ}\right)$ Ligaduras: - Leriche e sua Escola, nomeadamente StriCKer, Fontaine e Froelich, estudaram longamente a questão das ligaduras“e ressecções arteriais e o desenvolvimento da circulação colateral, chegando a resultados muito interessantes.

Verificaram que a ligadura progressiva, em andares, das artérias principais dos membros, determinava o desenvolvimento de uma circulação colateral que garantia perfeitamente a vitalidade dos tecidos. Verificaram, ainda, que a ligadura da aorta em um só tempo, logo acima dá sua bifurcação, acarretava a paralisia do trém posterior e a morte do animal. Isto já não se verificava quando a ligadura era acompanhada ou precedida da ressecção do simpático lombar. Esta ressecção tinha influência favorável decisiva sôbre o desenvolvimento da circulação colateral. '(figs.' 22 e 23)

Ligadura, é a operação mediante a qual o cirurgião descobre um vaso em um ponto estabelecido de antemão, de acôrdo com tempos operatórios perfeitamente definidos e oblitera por meio de um fio constrictor, ou para deter ou para evitar uma hemorragia, em outras palavras, hemostasia preventiva ou secundária. 


\section{Técnica geral:}

A) Material - Instrumental corrente: bisturí; pinças de dissecção, tesouras, afastađores de FARABEuF, tentacânula, agulha de DESCHAM PS, etc...

B) Tempos operatórios - Tôda ligadura arterial consta dos seguintes tempos:

a) incisão da pele e partes moles;

b) descoberta do feixe vásculo-nervoso e isolamento da artéria;

c) ligadura.

a) Incisão da pele e partes moles - Faz-se sôbre uña linha operatória estabelecida para cada artéria; esta- linha marca, aproximadamente, na superfície, o trajeto profundo do vaso. Para traçar tal linha serve-se de reparos fixos, ósseos ou musculares. Pesqui-

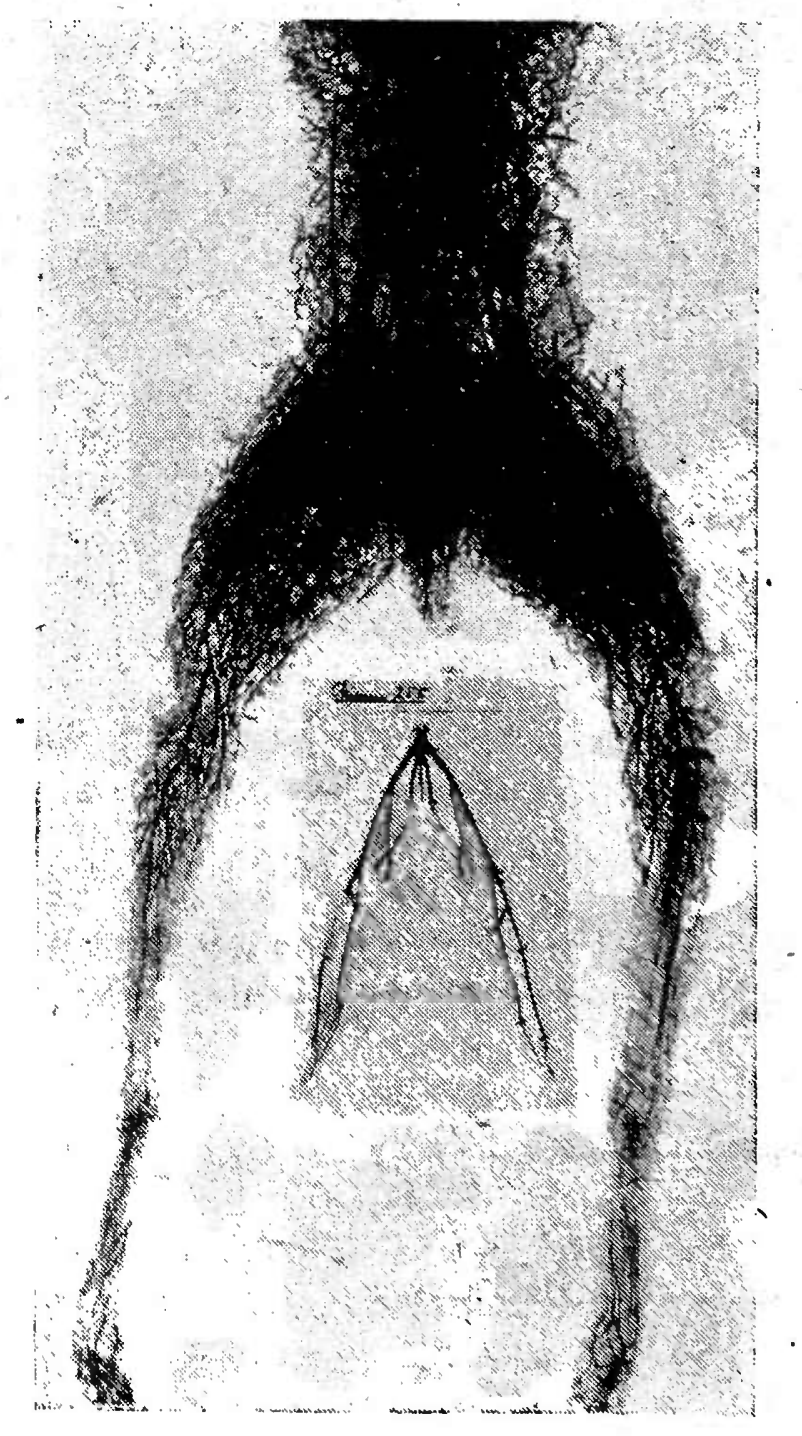

FIG. 22

Enorme desenvolvimento da circulação colateral, obtido por Leriche após ligadura e resseç̧ão das artérias principais, inclusive aorta abdominal. 
sados os pontos extrèmos da linha de operação, êstes são unidos, marcando sôbre a pele o traçado da mesma com violeta de genciana ou nitrato de prata. Seccionam-se pele e tecido celular, pingando os vasos que sangram e chega-se ao plano aponevrótico, que é igualmente aberto. Seccionada a aponevrose chega-se ao plano muscular.' Existem músculos que, apesar de não seguirem exatamente a direção de

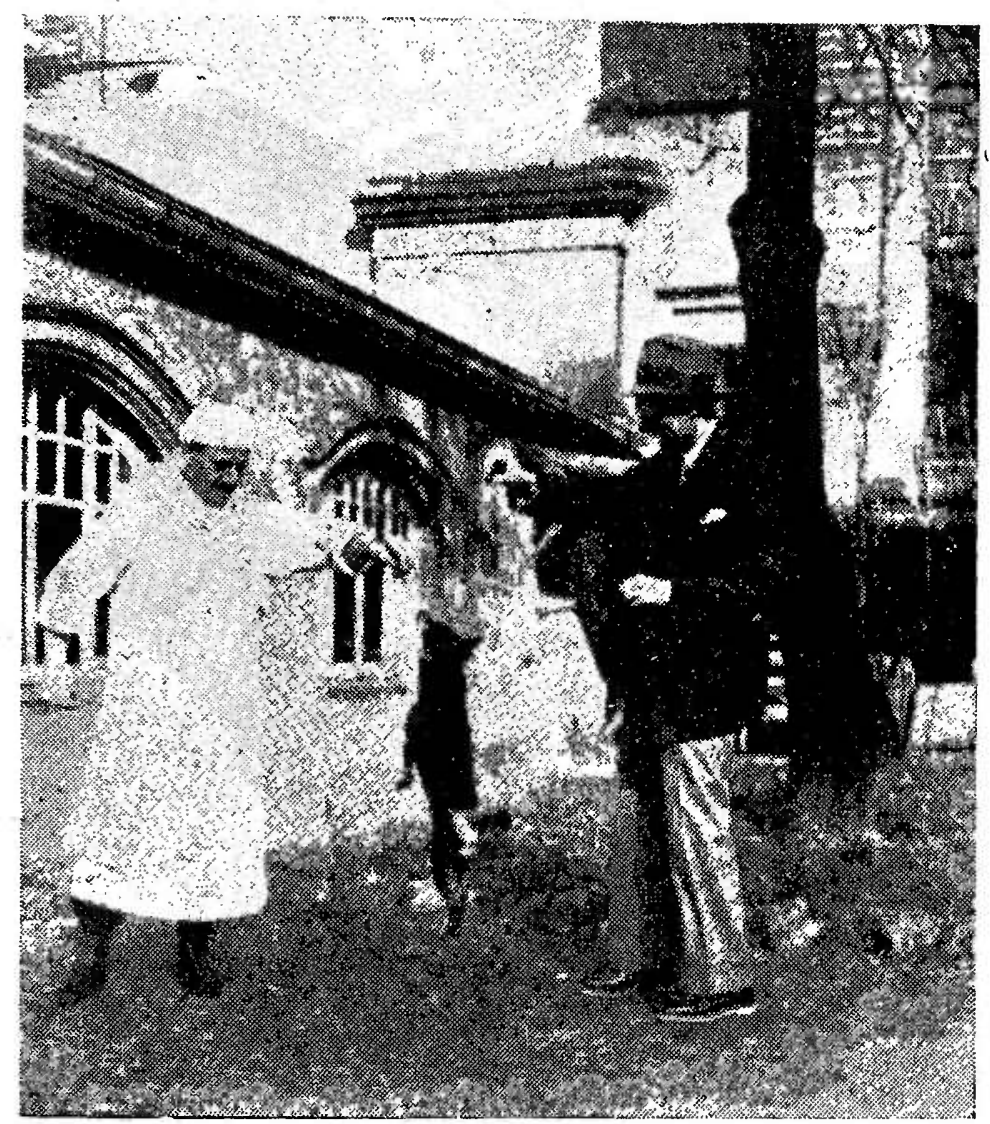

FIG. 23

Cão sem artérias, obtido na Clínica do Prof. R. Leriche. Foi ressecado em tempos sucessivos, todo o sistema arterial do cão, com exceção de alguns ramos da aorta abdominal

e carotidas. A irrigação dos membros é feita somente pela circulação colateral.

um vaso determinado, têm com êstes relações constantes que o cirurgião aproveita quando tem que ligá-lo; são os chamados músculos satélites da artéria correspondente; assim, o esterno-cleido-mastoideu é o músculo satélite da carótida, o costureiro é da femural etc...

b) Descoberta do feixe vásculo-nervoso e isolamento da artéria - A artéria é acompanhada, geralmente, por 2 veias e, às vezes, por um nervo, cujo conjunto constitue o chamado feixe vásculo-nervoso. Êste conjunto acha-se envolvido por uma baínha celulosa especial, a qual precisa, pois, ser aberta; a incisão de abertura deve ser feita sob tentacânula para evitar lesão vascular ou nervosa. Em seguida, é a artéria muito bem isolada dos outros elementos do feixe vásculo-nervoso. As manóbras precisam ser delicadas e poupando no mais possível a adventícia ou camada externa da artéria, que é a única resis- 
tente e que não se destroe ao se dar o nó de ligadura. Ūma vez isolada levanta-se a artéria e passa-se a agulha de Deschamps montada com catgut 1 ou 2, de acôrdo com o calibre maior ou menor do vaso. Retira-se a agulha é dá-se o nó.

O conhecimento completo das ligaduras de tôdas as artérias é inútil para o médico prático, pois a maioria delas não serão efetuadas. no exercício de sua profissão, já que em caso de fèrida de um vaso a indicação formal é a colocação de um laço ou atadura hemostática e a ligadura da mesma ao nível da ferida.

$2 .^{\circ}$ ) Sutura - As suturas que se executam nas paredes dos vasos arteriais são operações de técnica delicada, cujo objeto é ocluir uma ferida acidental ou operatória dos mesmos. Como já sabemos, as ligaduras não são destituídas de gravidade, levando por vezes o. membro, se não à gangrena, pelo menos a perturbações tróficas mais ou menos acentuadas. A ligadura de um grande tronco arterial deve, pois, ser considerada como anti-físiológica e, portantó, só teria indicação na impossibilidade técnica de recorrer à sutura, nas graves infecções ou na necessidade de acabar rapidamente a operação.

Indicações da sutura - Está indicada nas feridas parciais ou totais dos grandes vasos, cuja ligadura possa comprometer a vitalidade de um segmento determinado; isto é; naquelas artérias cuja ligadura habitualmente é bem tolerada, mas que é por vezes perigosa, como a subclávia, a axilar, a femural, a poplitéia e a umeral, as carótidas etc...

Contra-indicações da sutura - Nunca deve ser praticada em meio infectado ou mesmo duvidoso; iríamos expôr o membro à trombose, embolia, gangrena, hemorragia secundária, pioemia e morte. Não deve ser utilizada nos vasos de pequeno calibre porque, apesar de comumente ser inexequível, acarreta fatalmente a oclusão da luz do vaso, em nada se diferenciando, pois, de uma ligadura. Assim sendo, ela está contra-indicada nos ramos arteriais secundários, como a femural profunda ou as' artérias do ante-braço e da perna, depois de șua bifurcação.

Técnica geral - São condições imprescindíveis para o êxito dá sutura, as seguintes:

a) assepsia perfeita do foco; a sutura em foco séptico expõe a acidentes muito mais graves que a ligadura;

b) bordos nítidos e bem nutridos, para não efetuar a sutura sôbre partes traumatizadas;

c) afrontamento exato;

d) continuidade perfeita do revestimento endotelial do vaso. Em caso contrário, a menor solução de continuidade existente na luz do mesmo produziná ưna trombo'se, que trará a obliteração do vaso, fracassando neste caso a sutura.

e) escassa tração, para evitar as mortificações ao nível da sutura, as quais provocariam hemorragias secundárias. 
Material a usar - Além do material indispensável a tôda operação, necessita-se ainda: agulhas pequenas, de secção circular, que podem, ser curvas e montadas em pequenos porta-agulhas ou, preferentemente, retas. Para a compressão transitória dos vasos, utilizam-se pinças ligeiramenté elásticas, cujos ramos são envolvidos em tubos de borracha para proteger a parede do vaso, exercendo a compressão estritamente necessária para interromper a corrente sanguínea sem contundir a artéria. Esta pode também ser comprimida, como aconselha Haberland, utilizando um tubo de borracha e uma pinça hemostática ordinária. Em caso de necessidade, aplica-se ao redor do vaso uma tira de gaze sôbre a qual se anùda um fio de catgut grosso, ou bem comprime-se o vaso com uma tira de gaze, que-é mantida tensa utilizando uma pinça Para a sutura, utiliza-se seda muito fina, previamente introduzida em vaselina ou pomada de citrato de sódio e esterilizado em banho-maria. Dada a delicadeza dos instrumentos, o montar as agulhas é muito demorado, sendo preferível fazê-lo antes da operação, fixando as agulhas, já montadas, em uma tira de gaze. Todos os instrumentos utilizáveis são conservados, após a ebulição, em uma solução de citrato de sódio a $2 \%$, e os que vão entrar em contacto com a íntima são tratados com pomada de citrato de sódio (lanolina anidra, citrato de sódio, agua destilada, ãa 50; parafina líquida esterelizada 350). Também as compressas de gazes usadas são umideciđás em solução de citrato de sódio a $2 \%$.

Existem 2 tipos de sutura: parcial e total ou circular. A parcial se efetua quando existe uma ferida da parede que não interessa mais que a metade da circunferência; os bordos da ferida devem ser nítidos e não devem necessitar avivamento prévio. A sutura total ou circular executa-se nos seguintes casos:

a) ferida que compreende mais da metade da circunferência do vaso.

b) feridas irregilares.

c) perdas de substâncias e perfurações laterais.

d) secções circulares completas.

Técnica - A incisão deve ser ampla, o necessário para expồr o vaso a suturar em uma extensão não inferior a $10 \mathrm{cms}$. Isolado o vaso, procede-se à hemostasia por cima e por baixo da solução de continuidade por um dos métodos já nossos conhecidos.

Sutural parcial - Se a ferida reune as condições já citadas, pratica-se uma sutura parcial do seguinte modo:

Reparam-se os 2 extremos da ferida colocando 2 pontos, que servem de tracção para pôr tensa e retilínea a solução de continuidade. A sutura se faz começando pelo extrêmo distal, com material já indicado. Efetua-se uma sutura com pontos contínuos, que podem ser penetrantes ou não, isto é, interessar ou não a túnica endotelial; é preferível que não seja penetrante, pois o fio dentro da luz do vaso pode provocar uma trombose. Os pontos são feitos a 1 ou $2 \mathrm{mms}$. 
dos bordos da ferida e equidistantes uns dos outros. É muito importante não inverter os lábios da ferida, pois, neste caso, interromper-se-á a continuidade do endotélio vascular. E indispensável ao êxito da sutura, o contacto entre íntima e íntima. (fig. 24)

Sutura total - Tem as indicações já assinaladas. (fig. 25)

O melhor processo é o de CARREL, que se executa do seguinte modo: avivam-se as 2 superfícies de secção; Colocam-se ao-redor da circunferência do vaso, em cada um dos extremos, 3 pontos de seda, equidistantes entre si, os quais, ao serem postos em tração, permitem transformar a circunferência da secção em um triângulo equilátero. Nada mais falta que reunir os lados dêste triângulo por meio de uma sutura, como no caso da sutura parcial. Uma vez terminada a su-

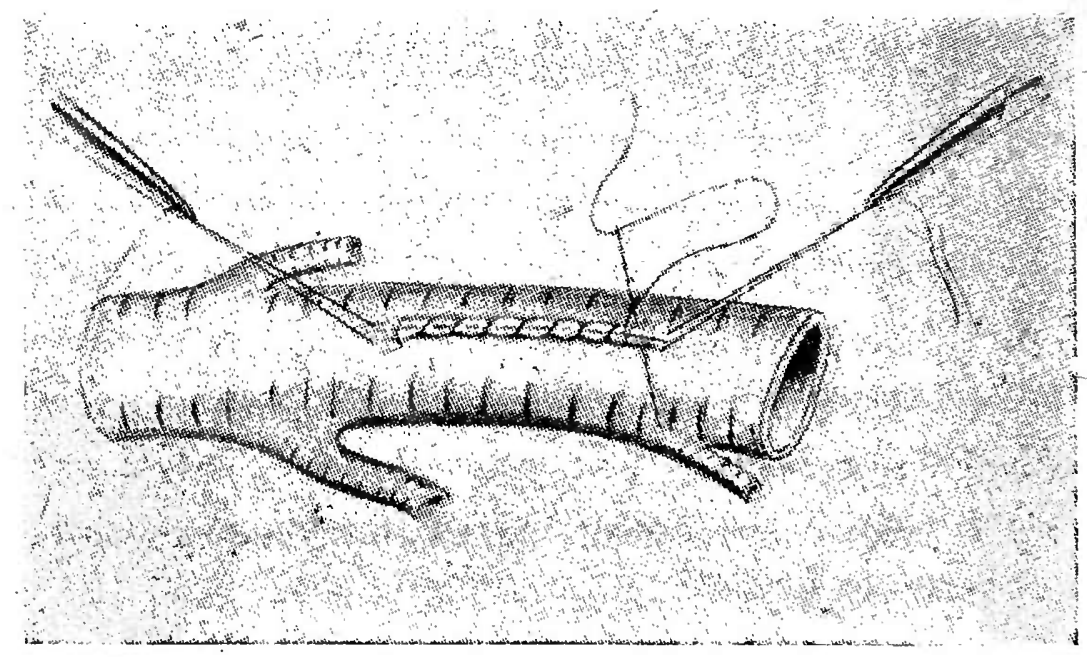

FIg. 24

Processo de Carrel para sutura longitudinal ou obliqua. (Bickham).

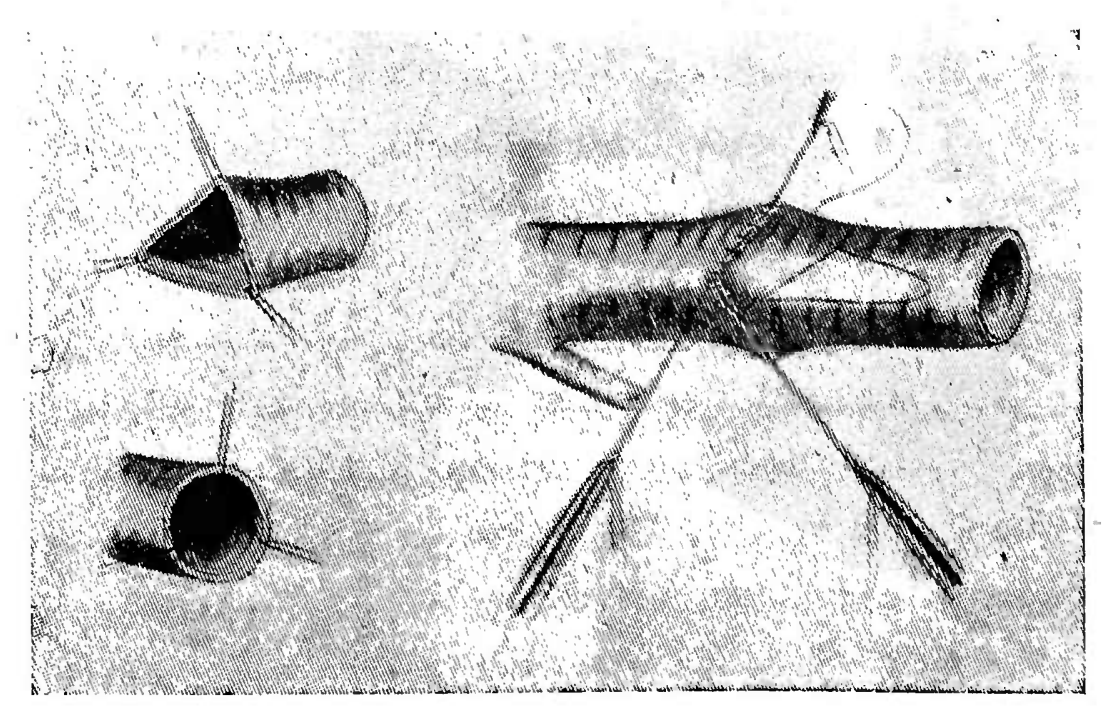

FIG.' 25

Processo de Carrel para sutura transversa total. (Bickham). 
tura, retira-se, nas artérias, primeiro a pinça do extrêmo periférico, logo a da parte central (nas veias as pinças são tiradas de modo inverso). Ha, em geral, um sangramento mais ou menos pronunciado; durante alguns minutos, com os dedos colocados sôbre as compresas contudo, esta hemorragia se coíbe logo com a compressão exercida, com gazes aplicadas na zona de sutura.

Quando o ferimento arterial é muito grande e ha perda de mais de $5 \mathrm{cms}$., a sutura está contra-indicada; pode-se, então, proceder a um enxêrto com veia safena. As suturas vasculares podem ser reforçadas com um fragmento de fascia lata, o que, porém, em geral, não é necessário.

Cuidad'os posoperatórios - Imobilização por 12 a 15 dias. Neste período, far-se-á medicação vaso-dilatadora para favorecer a circulação. É necesserário estar prevenido na eventualidade de uma hemorragia secundária.

3..$^{\circ}$ Arteriotomia - Consta da abertura seguida de nova oclusão da artéria; é feita quasi que exclusivamente para a extração de êmbolos (embolectomia). Frequentemente é difícil localizar a embolia. Neste particular é de grande valia a determinação dos pontos em que se percebe o pulso e onde êle se extingue, a exata exploração dos pontos dolorosos e resistentes no trajeto do vaso, a consideração da fórma e extensão da superfície cutânea fria, a modificação da coloração, transtornos tróficos, sensitivos e motores. Caso necessário, libertar-se-á a artéria em diferentes pontos e, por incisões exploradoras, examinar-se-á a praticabilidade dá corrente sanguínea procedente do coração. Quando existem várias embolias, na maioria dos casos só se conseguem determinar a localização da proximal.

A arteriotomia é praticada, sempre que possível, com anestesia local. Procura-se sempre libertar o segmento arterial obstruído. Se êste não for accessível, buscar-se-á a artéria em um ponto mais periférico e o mais próximo possível do mesmo. Por exemplo, em uma oclusão da aorta, na maioria dos casos, em atenção ao estado geral do doente, não é possível a libertação direta por laparotomia e se tentará extrair o êmbolo pela ilíaca primitiva ou ilíaca éxterna. Depois da libertação da artéria na zona obliterada, determina-se a localização exata do êmbolo e sua extensão para cima e para baixo, é, quando a localização corresponde a um ponto em que a artéria se bifurca, libertam-se os 2 ramoṣ que constituem a bifurcação, até à sua porção sã. Depois de aplicar uma pinça elástica no vaso aferente em sua porção sã, abre-se a artéria por uma incisão longitudinal, imediatamente por baixo e, só em caso de necessidade, na região do êmbolo, e, se êste não sair espontanamente, será extraído com cuidado com uma sonda, pinça ou curreta de extremidades rombas, cuidando ao máximo de não lesar o endotélio. Tais instrumentos devem ser tratados previamente com pomada de citrato de sódio. Uma vez extraído o êmbolo, pratica-se a arteriorrafia pela técnica habitual; uma vez terminada esta, examina-se a irrigação sanguínea do mernbro 
afetado e se esta não for satisfatória, será necessário verificar se não existe outra embolia.

Embolia da pulmonar - Já tivemos ocasião de dizer como se formam as embolias pulmonares: êmbolo que se desprende de um foco de trombose de uma veia periférica. Nos indivíduos em, que se verifica uma embolia pulmonar, a morte iminente e fulminante é a regra. Todavia, como muito bem diz TrendelenburG, em 50\% dos casos existe pelo menos um intervalo de 15 minutos éntre o início dos sintomas e a morte. Durante êste intervalo, póde-se praticar a·intervenção com sucesso; o êxito depende da maior ou menor rapidez com que ela é executada. KIRSCHNér cita um caso de sobrevida e Meyers 2. Como amanhã, no decurso de uma operação qualquer, uma extirpação de veia varicosa por exemplo, poderá surgir uma embolia pulmonar, é conveniente conhecer a técnica operatória.

A operação de TRendeleburg é feita por uma incisãó praticada no bórdo ésquerdo do esterno, do centro da qual outra é feita ao longo da $2 .^{\text {a }}$ costela. O tecido celular sub-cutâneo e as inserções do grande peitoral são disecados, a porção medial da $2 .^{a}$ costela com sua cartilagem costal é removida, e a cartilagem costal da $3 .^{a}$ costela é cortada e afastada para baixo. A pleura é incisada paralelamente e a $1 \mathrm{~cm}$. do bórdo do esterno, a artéria mamária interna é afastada lateralmente e o pericárdio é aberto. Exterioriza-se e hemostasia-se a pulmonar com um tubo de borracha compressivo. O garrote constritor abrange a artéria pulmonar e a aorta. A artéria é então incisada longitudinalmente, as margens da ferida se afastam, e o êmbolo é removido do vaso com um clamp curvo. Segundo Lawson e Sievers a artéria pulmonar não deve ser completamente obstruída por um período maior de 45 segundos; a incisão da artéria e a retirada do êmbolo não devem ultrapassar êste temipo. Com o auxílio de um clamp curvo revestido com borracha, é a porção incisada comprimida de maneira que permita a progressão do sangue no interior da artéria; a ferida do vaso é então fechada (figs. 26 a 29).

4..) Tratamento operatório dos aneurismas arteriais - $\mathrm{Na}$ escôlha da melhor terapêtutica aplicável a um aneurisma, é preciso lembrar 4 cousas importantes:

a) Nos aneurismas traumáticos, a bolsa aneurismal sempre. ultrapassá de muito os limites das lesões reais da artéria e engloba um segmento são de artéria, por vezes bastante longo, que é preciso evitar de sacrificar inutilmente.

b) $\mathrm{Na}$ bolsa abrem-se, em geral, colaterais, cuja obliteração é necessária para a cura do aneurisna. Essas colaterais tornam particularmente difícil a ablação de certos aneurismas, como aqueles que se assestam nas confluências vasculares, por ex.: no triângulo de Scarpa, na bifurcação carotidiana, no cavo popliteu en sua parte inferior. 


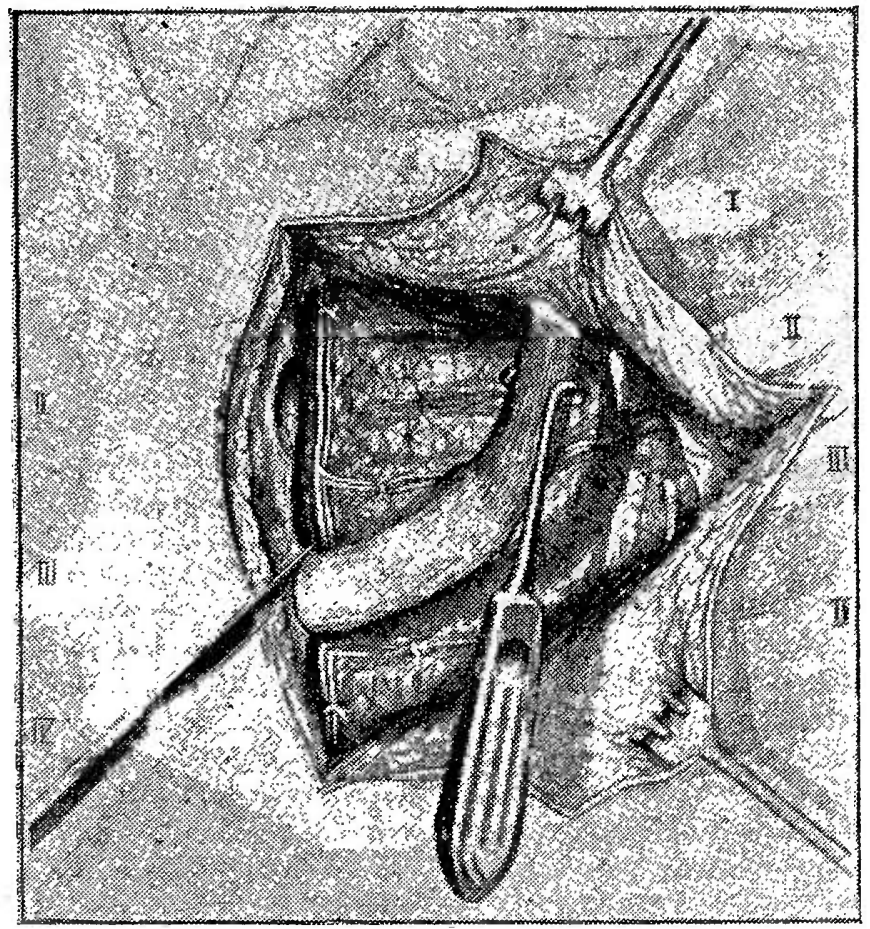

FIG. 26

Tipo de incisão e ressecção das $2 .^{a}$ e $3 .^{a}$ cartilagens costais. (Reid e Andrus, in Nelson).
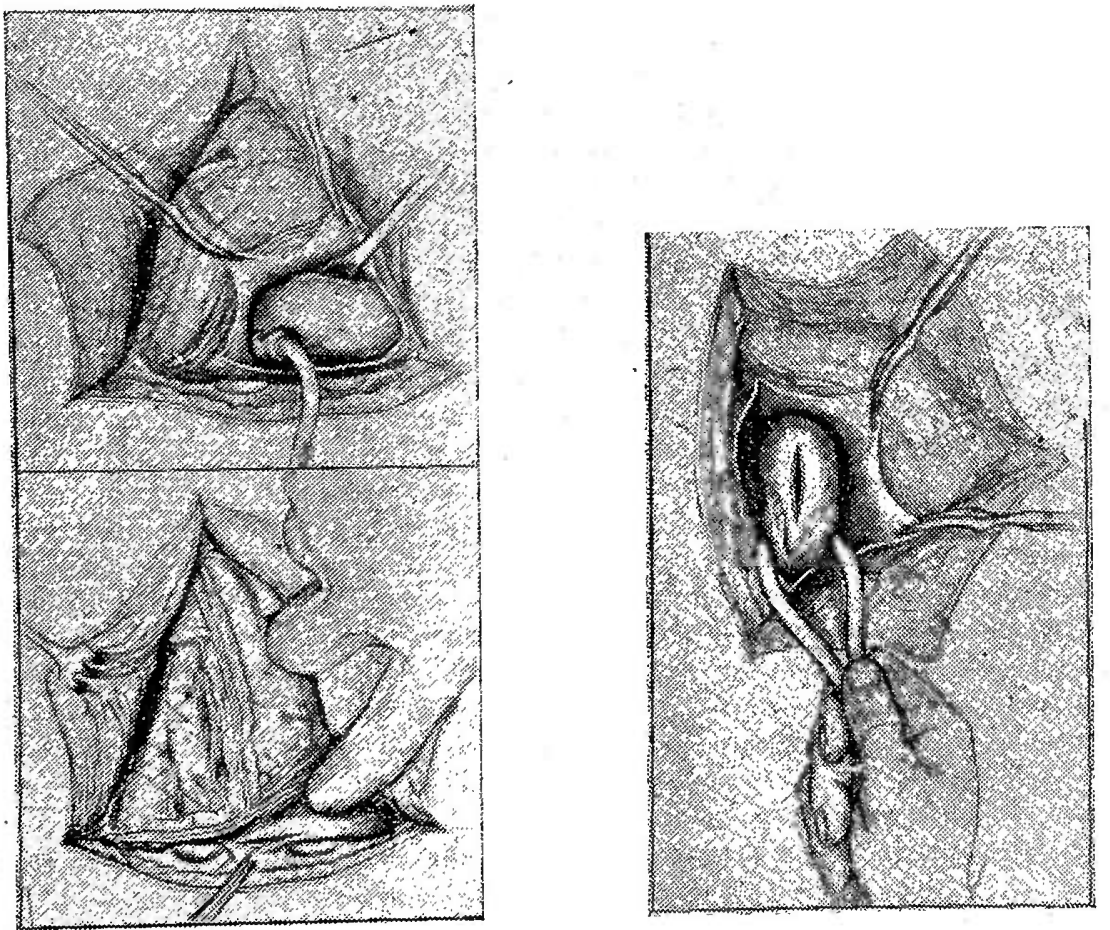

FIG. 27

A pleura e a artéria mamária interna foram deslocadas lateralmenté, e a incisão feita no pericárdio. Exposição da artéria pulmonar e colocação do tubo de compressão. (Reid e vaso. Incisão, na artéria pulmonar com o tubo hemostát 

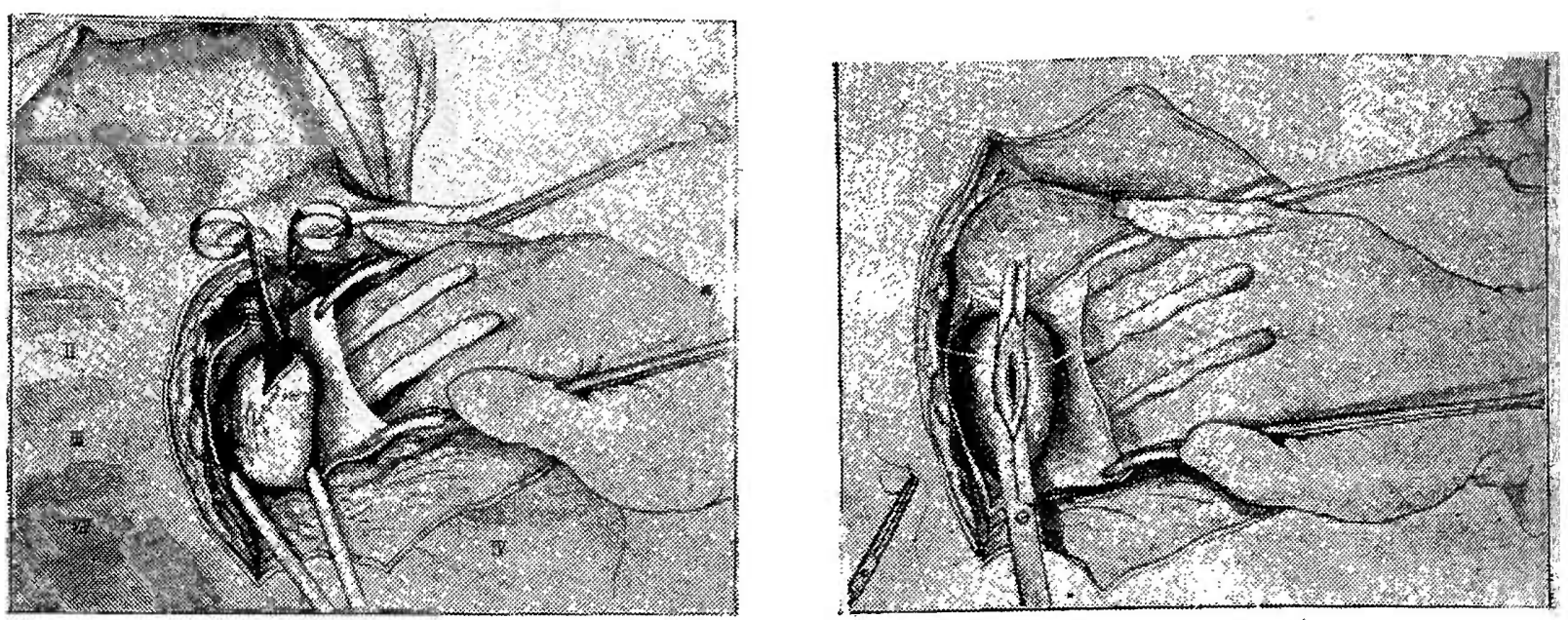

FIG. 28

Exploração da luz da artéria com um clamp especial; a hemostasia. é garantida por tracção sôbre o tubo. A figura colocada abaixo, mostra o método de fechamento da artéria pulmonar na frente do clamp curvo revestido de borracha, que foi aplicado no vaso, tangencialmente, afim de permitir a circulação pela luz restante. (Reid e Andrus, in Nelson).

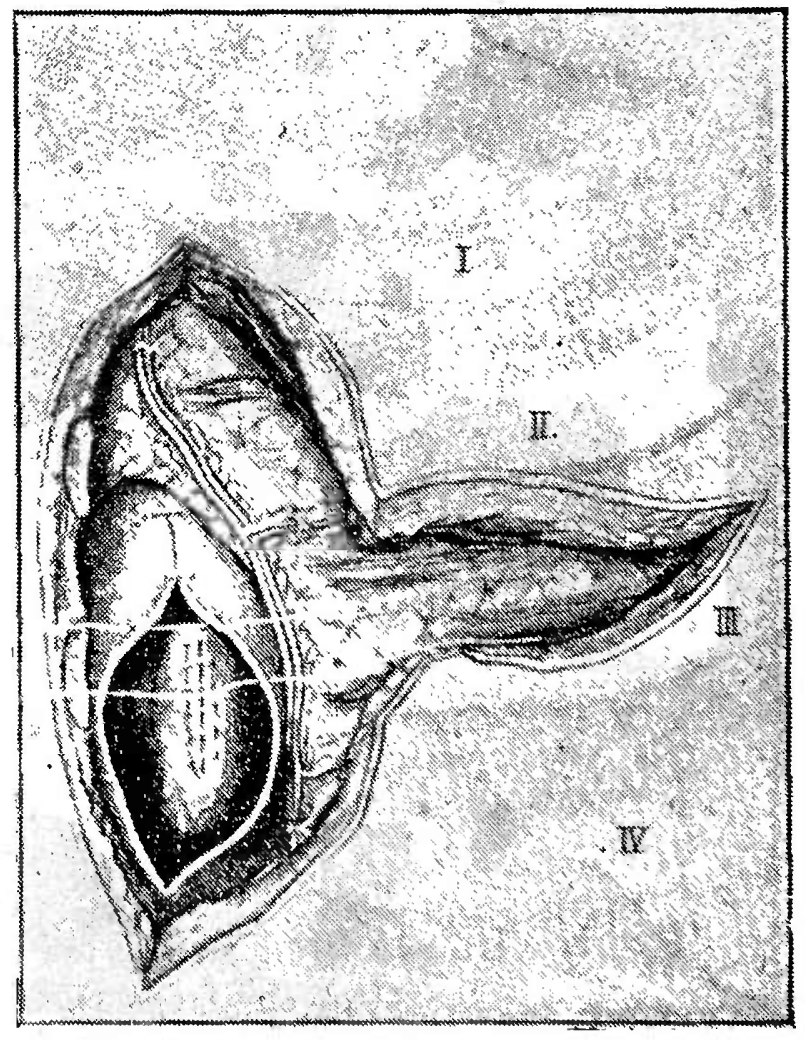

FIG. 29

Artéria pulmonar suturada e maneira de se fechar o pericárdio. (Reid e Andrus, in Nelson). 
c) O saco apresenta conexões estreitas com os órgãos vizinhos, com os nervos em particular. Êstes, por vezes, não são afastados, mas sim englobados no tecido inflamatório crônico que se desenvolve ao redor do aneurisma. Êles não podem ser libertados a não ser pela supressão da bolsa.

d) $\mathrm{O}$ saco apresenta coágulos no seu interior, que poden facilmente, no curso das manipulações operatórias embolizar a periferia.

Uma vez diagnosticado um aneurisma arterial, inicia-se' sistematicamente o tratamento anti-sifilítico se êle não foi traumático e trata-se-o cirurgicamente o mais cêdo possível. Os métodos operatórios são inúmeros, e daremos somente aqueles que já se tornaram clássicos e que podem ser resumidos assim:

A) Método das ligaduras $\left\{\begin{array}{l}\text { completas } \\ \text { incompletas }\end{array}\right.$

B) Incisão do sacó entre 2 ligaduras (métodos de ANtyllus)

C) Extirpação, com ou sem restauração da continuidade arterial.

D) Endo-aneurismorrafia de Mitas.

A) Método das ligaduras - Existem 2 tipos de ligadura: a. ligadura incompleta e a ligadura completa clássica.

a) Ligadura completa - Ela pode ser feita acima ou abaixo. do saco. Logo acima, é o processo de ANer; à distância, deixando. uma ou várias colaterais entre as ligaduras e o aneurisma, é o processo de Hunter; logo abaixo, é o processo de Brasdor; ou à distância, deixando colaterais entre o saco e a ligadura, é o processo de WARDRop. (A figura 30 esquematiza os diferentes processos: 1. Ligadura de Hunter - proximal; 2. ligadura de ANEL - proximal; 3. ligadura de BrASDOR — distal; 4. ligadura de WARDROP - distal).

Crítica - Feita a montante, a ligadura pode ser completamente inútil se por acaso o aneurisma se assesta sôbre uma colateral em contacto com o tronco principal e não sôbre êle; ela é igualmente praticamente inútil se existem, no caso, colaterais por onde continuará a afluir sangue para o interior do aneurisma; caso ela cure o aneurisma, deixará no entanto, o saco cheio de coágulos, que, organizando-se conjuntivamente, terão uma ação esclerosante sôbre tudoque o envolve; paralisias e dores seguir-se-ão à operação; o resultado funcional será, pois, medíocre. Demais, ela é sempre perigosa, não para a vida, más para o membro, porque ela favorece a gangrena, seja por supressão brusca do sangue na via principal, se se ligar uma grande artéria, seja facilitando as embolias partidas do saco e projetada no segmento arterial inferior por afluxo de sangue vindo das colaterais. De fato, a gangrena é frequente apoós a ligadura. (fig. 31) 


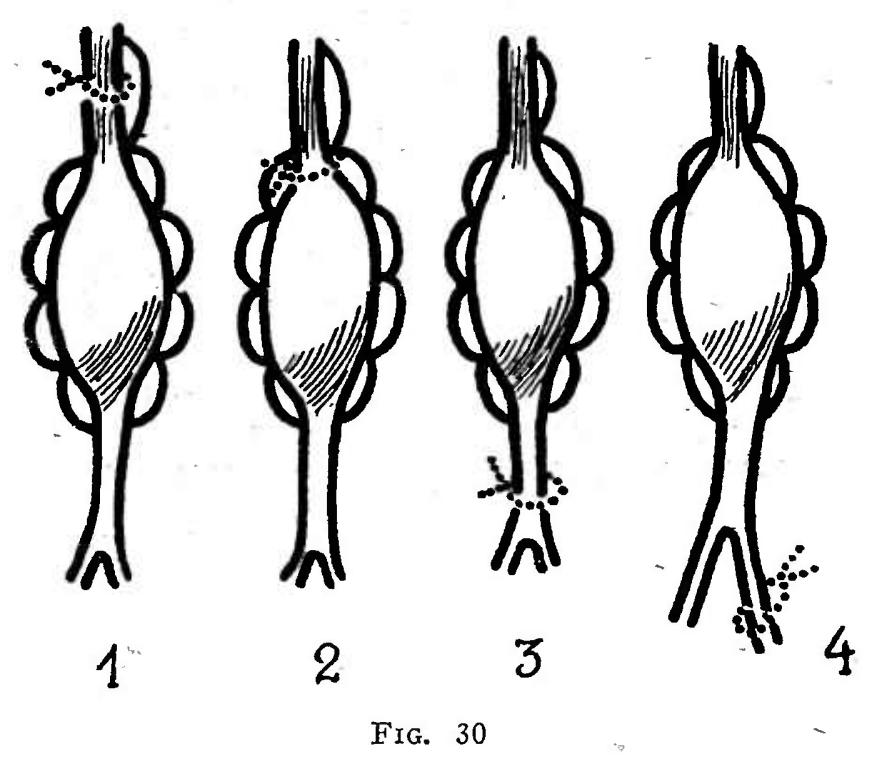

Vários métodos de ligadura no tratamento dos aneurismas (Matas). 1 - ligadura de Hunter-proximal. 2 - ligadura de Anel-proximal. 3 - ligadura de Brasdor-distal do tronco. 4 - ligadura de Wardrop-distal do ramo do tronco. (Reid e Andrus, in Nelson).

Feita a jusantè, a ligadura não é tão perigosa, mas é ainda muito mais ineficaz, pois as colaterais entretêm perfeitamente a circulação no saco. Concluindo: a ligadura completa deve ser rejeitadaem todos os aneurismas onde se possa aplicar um outro método qualquer. Se para os membros isto é verdade, o mesmo não se pode dizer dos aneurismas da parte interna da base d opescoço e para os da bacia, onde ela constitue o unico método praticável. A ligadura completa da primeira porção da sub-clávia, da ilíaca primitiva etc... se acompanha muito frequentemente de gangriena. Foi querendo evitar êstes perigos que MAtas e Allen, bem como Halsted, propuseram a ligadura incompleta dos grandes vasos em casos de aneurismas.

b) Ligadura incompleta - Como o próprio nome indica, consta o processo da prática de uma ligadura que não oclua completamente a luz do vaso; o fio fica frouxo, diminuindo a luz vascular. Halsted e Matas, os primeiros executores, usam fitas metálicas flexívies de alumínio, que são aplicadas por instrumentos especiais. LERICHE usa a seda grossa. A operação está particularmente indicada nos aneurismas muito volumosos dos grandes vasos, ao nível dos quais a operação direta, de qualquer tipo que seja, é perigosa (grandes aneurismas ínguino-crurais, aneurismas da base do pescoço, do tronco bráquio-cefálico, da aorta...). Em geral, ha grande diminuição do volume do aneurisma, se não a cura completa; caso esta não se verifique, poderá o mesmo ser extirpado em um segundo tempo. À primeira vista, o método choca um pouco; no entretanto, cirurgiões de renome, como Halsted e Matas, principalmente êste último, que possuem grande prática, grande casuística e são grandes estudiosos do assunto, chegam a afirmar que, pelo 

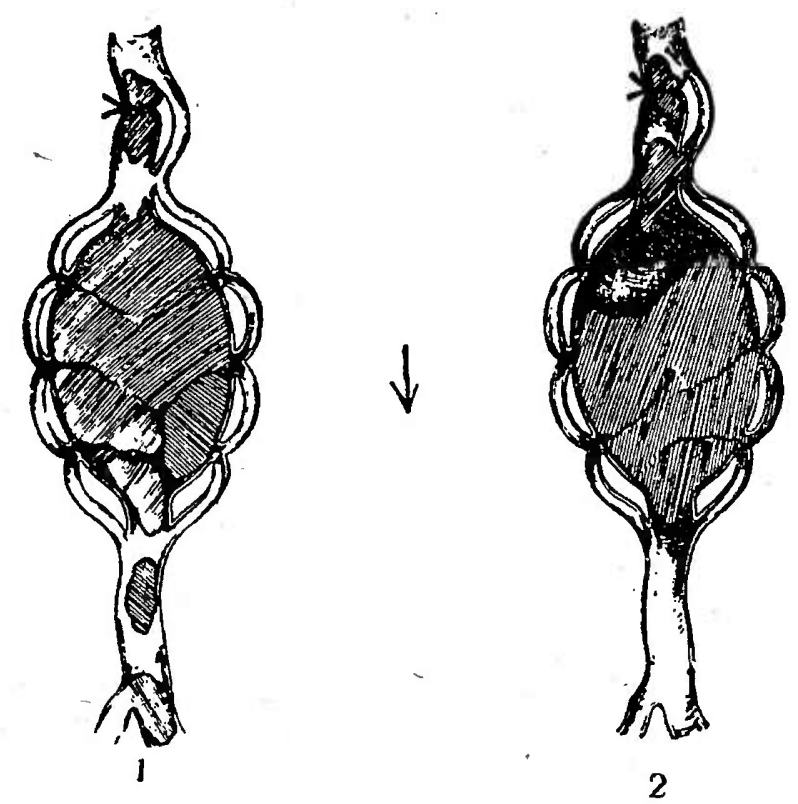

FIG. 31

Diagrama mostrando como uma gangrena periférica pode ocorrer após uma ligadura proximal. Massas de coágulo (êmbolos) são destcadas da cavidede aneurismática para ficarem retidas na bifurcação do tronco principal. No aneurisma da artéria poplitéia, as artérias tibial anteror e posterior podem ser bloqueadas simultaneamente, produzindo gangrena. (Reid e Andrus, in Nelson).

menos em $80 \%$ dos casos, a óclusão incompleta da artéria nutriente é suficiente para produzir a cura radical do aneurisma. (fig. 32)

B) Incisão do aco entre 2 ligaduras - Metódo de Antylıus - Os pontos essenciais desta operação são ligadura da artéria em nível imediatamente proximal e distal ao aneurisma, e evacuação do conteúdo do aneurisma através de uma incisão no saco (2, fig. 33), que não é removido. Quando a hemorragia é muito grande, ligam-se as colaterais externamente ao saco. $O$ processo não é mau; não constitue, porém, um método de escôlha: deixa como "reliquat" fenômenos dolorosos devido ao repuxamento dos nervos peri-vasculares após retração cicatricial do saco, expõe o membro à gangrena, caso a circulação colateral não seja suficiente.

C) Extirpação com ou sem restauração da continuidade arterial - Em linhas gerais, consta o método do seguinte (técnica de Purmann) :

a) ligaduras proximais acima e abaixo do aneurisma, extirpação do mesmo após ligadura das colaterais e libertação dos tecidos vizinhos (3, fig. 33). 'Êste método não se preocupa com a continu1dade arterial. Póde-se, porém, usar:

b) clamp hemostático revestido com borracha, acima e abaixo do saco aneurismático, extirpação do mesmo como no processo anterior, sutura término-terminal dos 2 extremos arteriais pela técnica 
de Carrel (fig. 34). Quando a perda de substancia é muito grande, lança-se mão dos enxertos com veia safena interna, por exemplo. Êste é o restaurador da luz vascular.

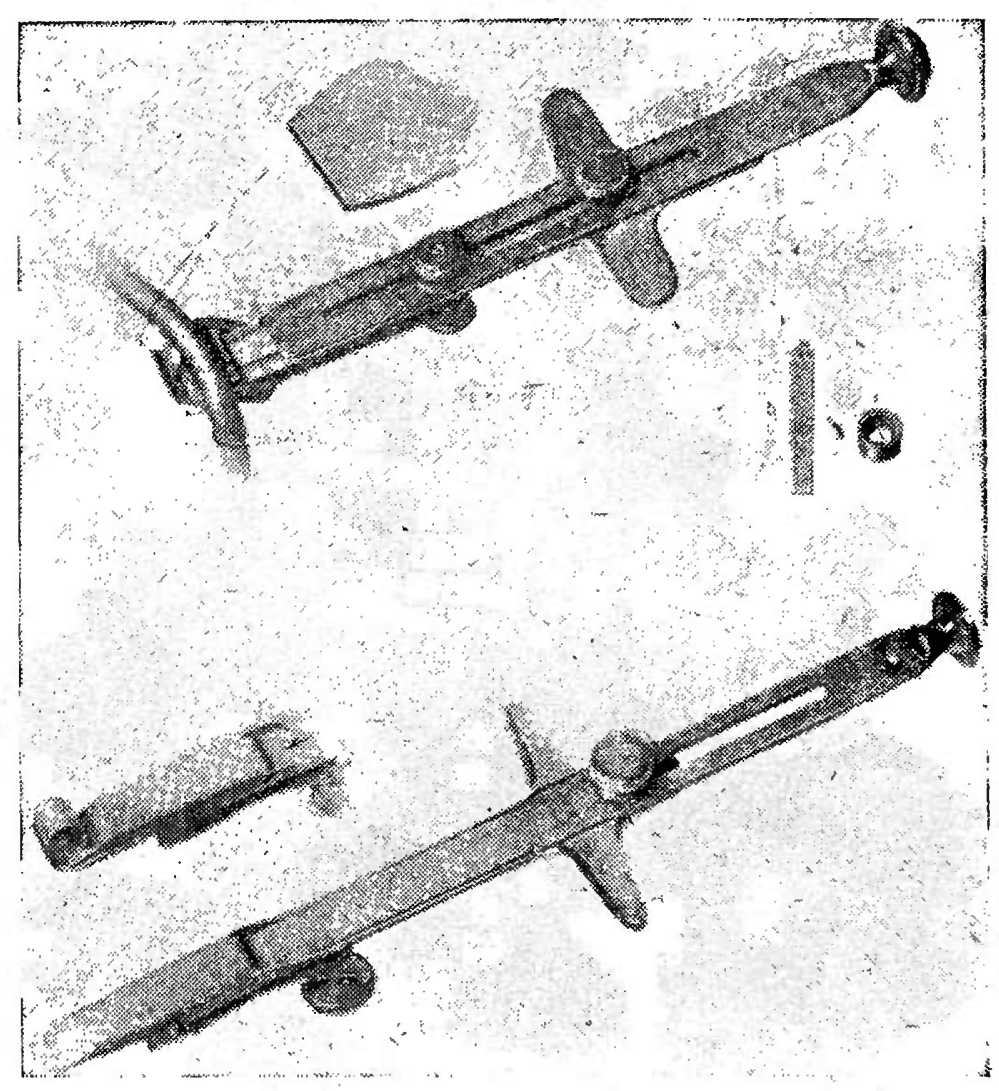

Fig. 32

Instrumento de Halsted para ligaduras incompletas. (Reid e Andrus, in Nelson).
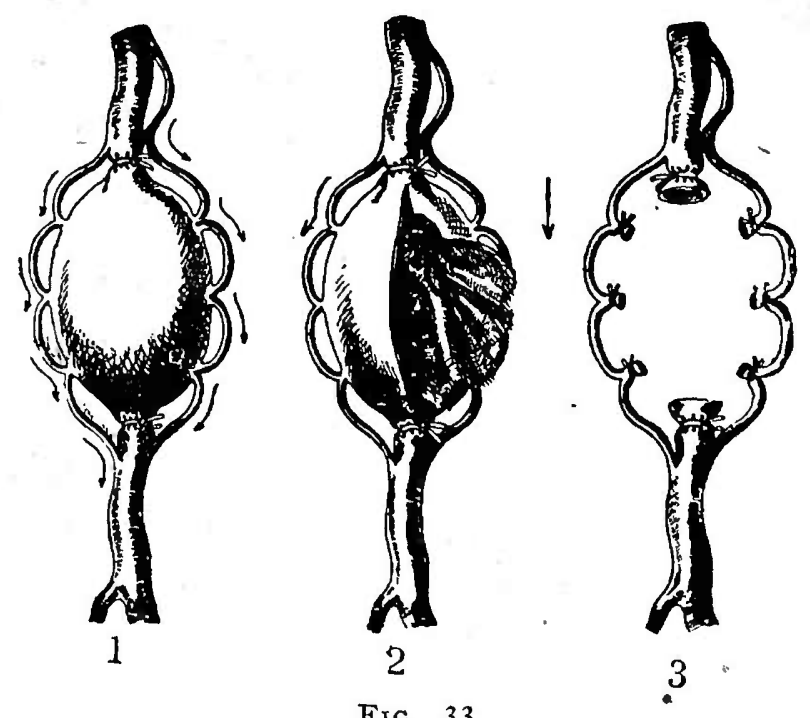

FrG. 33

1 - ligadura bipolar do tronco principal do lado proximal e distal to aneurisma (método de Pasquin), mostrando como o saco pode ainda ser nutrido pelas colaterais. 2 - operação de Antyllus: ligadura bipolar do tronco principal com incisāo do saco, mostrando cono pode ocorrer uma hemorragia primária ou secundária em caso de circulação abundante. 3 - operaçāo radical por extirpação do saco (operação de Philagrius ou de Purmann), mostrando como a circulação pode ser mantida. (Reid e Andrus, in Nelson). 


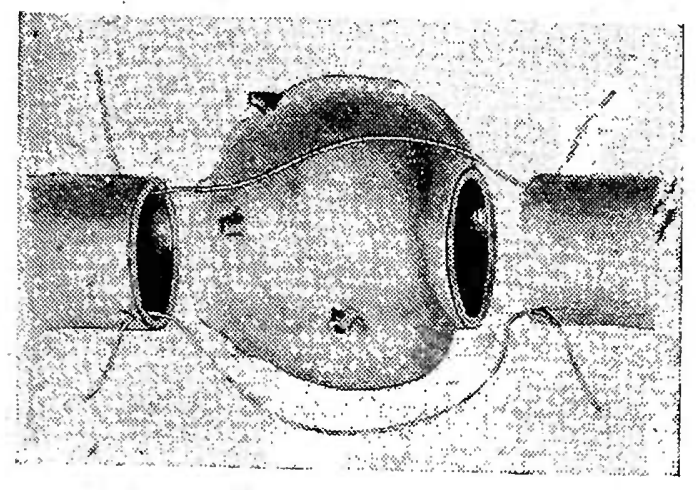

Frg. 34

Extirpação do saco com restauração da luz vascular. (in Kirschner).

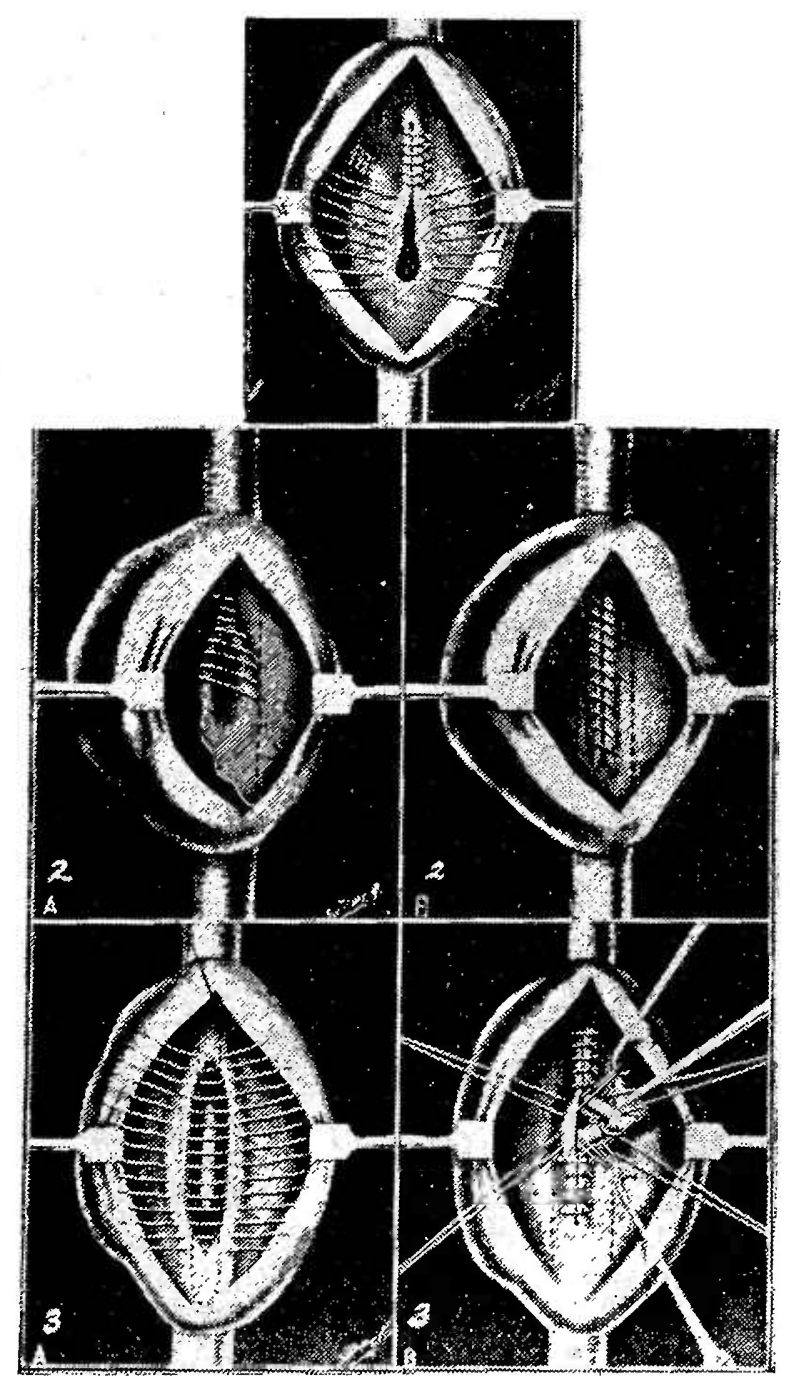

FIG. 35

Aneurismorrafia de Matas. 1 - endo-aneurismorrafia obliteradora. 2 - endo-aneurismorrafia restauradora. 3 - endo-aneurismorrafia reconstrutora. (Reid e Ándrus, in Nelson). 
Crítica - A aneurismectomia, com sutura término-terminal dos 2 extremos arteriais, constitue o método ideal: extirpa o aneurisma e assim evita as dores posoperatórias provocadas pelo estiramento nervoso do processo cicatricial; a circulação continúa a se processar regularmente, não havendo perigo de gangrena. Deve ser praticado sempre que possível.

D) Endo-aneurismorrafia de Matas - Existem 3 tipos de endo-aneurismorrafia :

a) endo-aneurismorrafia obliteradroa;

b) endo-aneurismorrafia restauradora;

c) endo-aneurismorrafia reconstrutora.

a) Endo-aneurismorrafia obliteradora (1, fig. 35) - Consiste em se abrir o saco aneurismático com uma incisão longitudinal sem nenhuma dissecção preliminar; praticar então, no interior do saco, o fechamento de todos os orifícios arteriais com catgut fino ou seda. A hemostasia prévia, pelo Esmarch ou por 2 clamps, um abaixo e outro acima, torna-se imprescindível. Quando se procede ao fechamento dos orifícios arteriais, não se faz questão de conservar a luz dos vasos, (daí dizer-se obliteradora). Após a oclusão dos orifícios arteriais, o saco e os espaços mortos são totalmente obliterados por meio de suturas por pregueamento, sendo, em seguida fechada a pele, sem drenagem.

b) Endo-aneurismorrafia restauradora (fig. $35-2$. A. B.) - Êste processo só é aplicável no tratamento dos aneurismas sacciformes não infectados. Após abrir o saco e limpar a sua superfície interna de todos os coágulos, a abertura lateral da artéria é suturada com catgut cromado ou seda, tomando-se o cuidado de não obliterar a luz do vaso (o método é restaurador). - O saco é então obliterado como no processo anterior. Matas aconselha o uso desta técnica não somente nos casos típicos de aneurisma sacciforme, mas, igualmente, naqueles aneurismas onde existir um sulco ou uma goteira profunda, estendendo-se do início ao final do saco. A grande vantagem do método é a restauração do tronco arterial principal.

c) Endo-aneurismorrafia reconstrutora (Fig. 35 - 3. A. B.) — E aplicável somente nos aneurismas fusiformes, cujas paredes são firmes, elásticas e maleáveis, podendo, assim, ser utilizadas na feitura de um novo vaso. Contudo, a execução desta operação está na dependência das duas aberturas arteriais; estas devem se encontrar no mesmo plano e devem ser facilmente accessíveis. Um catéter ou um tubo de borracha é usado como guia durante - a reconstrução da artéria.

Critica das endo-ancurismorrafias - Têm o defeito de deixar o saco "in situ" e, portanto, apresentar os mesmos inconvenientes que o método de Antyllus: persistência de perturbações nervosas, dores e paralisias. Alega, porém, Matas que o saco aneurismal, no 
final de alguns meses, é, se não totalmente absorvido, reduzido a tão pequenas dimensões que não provoca perturbação alguma.

Segundo MAtas, grande autoridade no que diz respeito aos. aneurismas arteriais, e Leriche, grande entusiasta da cirurgia vascular, constitue, a endo-aneurismorrafia, o melhor método de trataménto cirúrgico do aneurisma arterial. O método de PurmanN (aneürismectomia + restauração) constitue, sem dúvida, o método ideal, mas é de execução difícil e, na maioria dos casos, irrealizável.

Indicações e escôlha do processo - Torna-se indispensável, antes de mais nada, saber quais as condições da circulação a jusante do anẹurisma; só assim poderemos avaliar da indicação ou da. contra-indicação formal dos' diferentes processos estudados.

Assim :

a) $O$ desaparecimento do pulso abaixo do aneurisma inclica. que a circulação de suplência está bem estabelecida, e, em consequência, a obliteração do segmento aneurismal não teria perigo para a vitalidade da extremidade. Pelo contrário, um pulso normal, bem conservado abaixo de um aneurisma, deve contra-indicar formalmente tôda ligadura e impôr a reconstrução. da artéria.

b) A oscilometria com o aparêlho de PACHON deve ser pesquisada: se a pressão a montante for baixa, com máxima abaixada e oscilações fracas, o prognóstico não será mau. Se a pressão for forte, concluir-se-á que pelo menos a maioria da circulação do membro se faz pelo aneurisma; sua supressão brusca poderia ser desastrosa.

Com estas diferentes provas estamos mais ou menos orientados: na éscôlha do método a empregar. Sempre que possível, porém, deve-se ter preferência pelos métodos de Purmans e de Matas.

$5^{\circ}$ ) Tratamento cirúrgico dos aneurismas artério-venosos $\mathrm{O}$ objetivo do tratamento dos aneurismas artério-venosos deve ser sempre a supressão da comunicação artério-venosa e ela é uma das. condições de sucesso.

Para isto dispomos de 4 métodos:

A) Ligadura quádrupla;

B) extirpação com ou sem restauração vascular;

C) separaçộes artério-venosas, com suturas laterais;

D) aneurismorrafia de Matas.

a) Ligadura quádrupla - Como o seu nome indica, consta o método da ligadura da artéria e da veia, acima e abaixo da fístula. E evidente que o processo só pode ser eficaz quando não existe, no segmento bivascular, nenhuma colateral arterial capaz de trazer sangue em quantidade suficiente. Além do mais, o bloco excluído retraindo-se, irrita os nervos vizinhos, esclerosa-os, age sôbre o simpático peri-arterial e cria, assim, sérias dores. No dizer de DELBET, a recidiva é fatal nas regiões onde as colaterais arteriais são numerosas, como por exemplo: carótida primitiva na sua bifurcação, fe- 
mural comum perto de sua divisão, poplitéia nas vizinhanças do tronco tíbio-peroneiro e da tibial anterior. Em resumo, deve-se considerar a ligadura quádrupla como um meio de acabar uma extirpação que foi dada como irrealizável durante o ato opèratório. Como diz Leriche: on peut la faire; elle n'est pas ce qu'il faut faire.

B) Extirpação, com ou sem restauração vascular:

a) Extirpação - Faz-se uma ligadura quádrupla e extirpa-se o aneurisma após a ligadura das colaterais. O processo não é mau desde que haja uma ampla circulação colateral de suplência; caso contrário, exp̃õe o membro à gangrena.

b) Extirpação seguida de restabelecimento da luz vascular: hemostasia prévia com Esmarch ou clamps revestidos de borracha; secção da artéria e, em seguida, da veia, acima e abaixio do aneurisma, reconstituição da luz vascular por sutura termino-terminal artério-arterial e veno-venosa. É o métödo ideal e o mais anatônico, porém, de uma excequibilidade raríssima, devido às dificuldades técnicas. Existem algumas variantes

a) resseca-se ë sutura-se a artéria e, em seguida, ligam-se os segmentos da veia.

b) a perda de substância foi superiọ a $5 \mathrm{cms}$., a sutura circular término-tèrminal é impossível; lança-se mão do enxêrto simples ou duplo com veia safena où outro qualquer material.

C) Separação artério-venosa seguida de angiorrafia - São as operações de escôlha, pois que realizam a supressão da comunicação artério-venosa e o restabelecimento completo da circulação no tronco arterial. As principais modalidades técnicas são as seguintes:

a) ligadura do canal de comunicação - Obliterar o canal, ligando-o ou cortando-o entre duas ligaduras: Só é realizável naqueles casos em que existe uma disposição anatômica favorável, o que não é o comum.

b) suturas laterais - Separam-se os dois vasos e pratica-se uma sutura lateral na artéria e 'na veia (fig. 36 ; caso não se consigna praticar a fleborrafia, procede-se à ligadura da veia, o que não traz inconvenientes.

D) Endo-aneurismorrafia de Matas - Hemostasia prévia com Esmarch ou clamps revestidos com borracha; incisão longitudinal da veia e fechamento do orifício fistuloso, internamente, com uma sutura contínua (fig. 37). Havendo 'um saco aneurismático interposto entre os. dois vasos, pratica-se, agora, não mais a venọtomia, mas sim a abertura da parede anterior do saco intermédio, suturando-se, em seguida internamente, os dois orifícios comunicantes (fig. 38).

Indicações e escôlha do processso - À escolha do processo antepõe-se uma questão até hoje muito discutida: em princípio, deve-se operar todos os aneurismas artério-venosos, salvo contra-indicação geral; contudo, deve a operação ser precoce ou tardia?. 
Em certas instâncias: hemorragia, hematoma progressivo, infecção, sintomas cardíacos agudos etc... deve-se operar logo após o acidente. Desde que nada disto se verifique, o melhor é

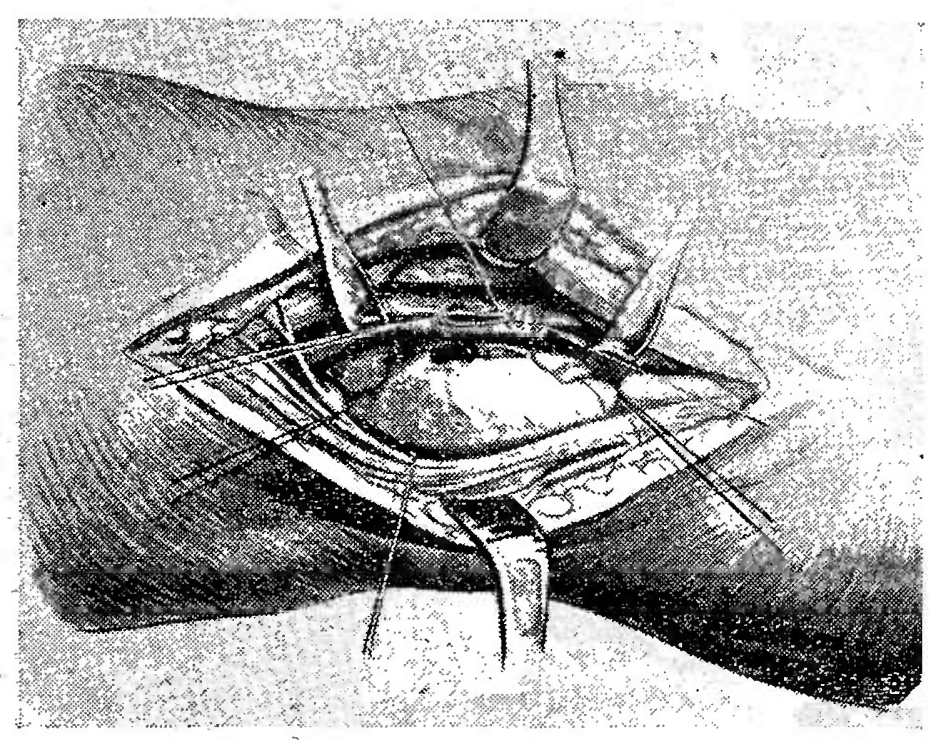

FIG. 36

Separação artério-venosa se. guida de suturā lateral $\mathrm{da}$ artéria e da veia.
FIG. 37

Endo-aneurismorrafia praticada após venotomia. (Reid e Andrus, in Nelson).

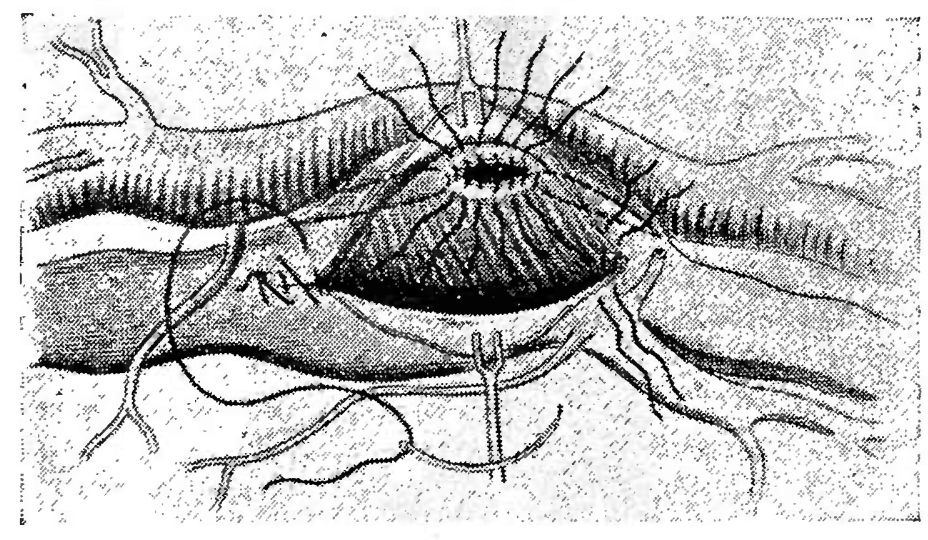

FIG. 38

Aneurisma artério-venoso com saco aneurismático interposto. Praticou-se a abertura do saco e em seguida, $\dot{a}$ endo-aneurismorrafia de Matas. (Reid $e$ Andrus, in Nelson). 
esperar alguns meses, 4 a 6 ; as vantagens, segundo REID e ANDRUs, são inúmeras:

a) ha desenvolvimento acentuado da circulação de suplência, o que permite a excisão da fístula sem temor de gangrena (em um cão, ligou-se a femural esquerda e praticou-se uma fístula artério-venosa fêmulo-femural dîreita; houve maior-desenvolvimento da circulação colateral no membro com fístula do que naquele com ligadura).

b) os vasos lesados curam-se completamente, tornando, então, sua dissecção muito mais fácil.

c) a infecção da ferida é mais difícil, pois que o hematoma já foi absorvido e os tecidos voltaram ao normal.

d) alguns casos curam-se espontaneamente nos primeiros 6 meses.

e) as perturbações podem se abrandar a ponto de não mais justificarem uma intervenção cirúrgica (particularmente do membro superior).

A operação decidida, qual o processo a escolher? Em princípio, evidentemente, as operações restauradoras da continuidade arterial. Entre estas, deve-se dar preferência à separação da comunicação seguida de angiorrafia e ao método de MATAs. Não se pode, porén, ser radical; ainda a melhor conduta é ser écletico e escolher os meios mais simples de se chegar à supressão do mal. Nunca se deve esquecer das palavras de Matas: Nos truamatizados jovens e sãos, podemos ir bem longe na conquista do ideal; mas, nos velhos ou nos indivíduos maduros, onde os aneurismas se desenvolvem como prova de sua degenerescência arterial, é preciso ser prático: o ideal téçnico e fisiológico deve ser subordinado às exigências primordiais da proteção da vida. É melhor ficar satisfeito com um. sucesso imperfeito ou parcial que ter um desastre completo.

\section{CARDIOSCLEROL TONICO CARDIACO ATOXICO HIPERTENÇÃO ARTERIAL - MIOCARDITES - ARTERIOESCLEROSE A base de Viscum album - Cactus grandiflora - Cratoegus - Kola - Scila Rodanato de Potassa \\ Amostras e literaturas a disposição dos srs. Medicos}

C.AIXA, 4500 


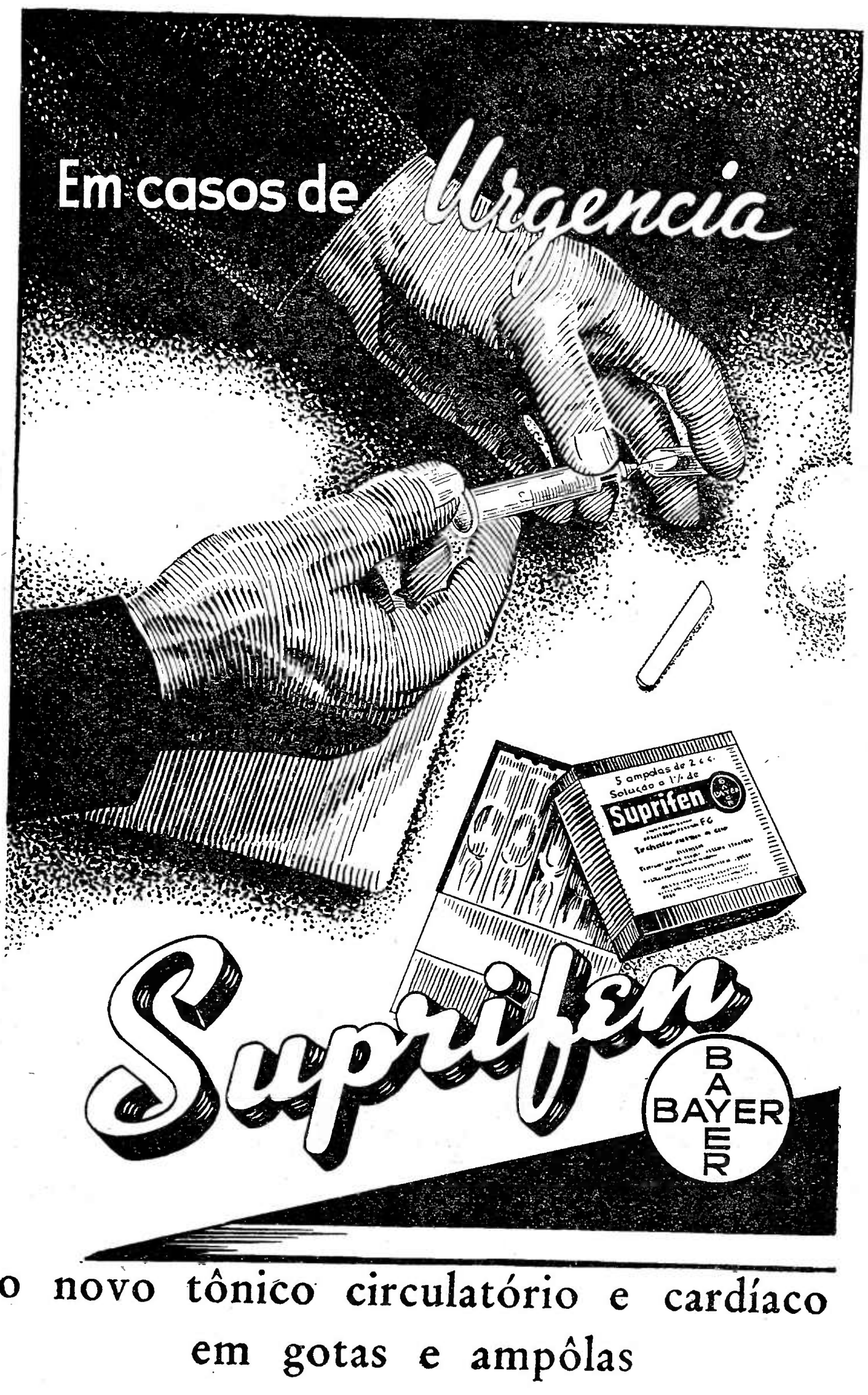




\section{DEXTROSOL}

( $G L U C O S E-d$ )

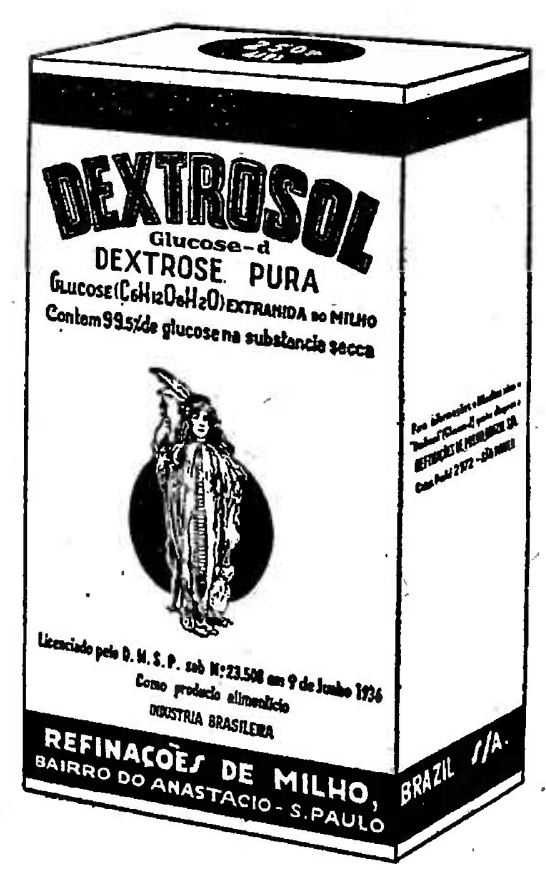

"DRENA AGUA DOS TECIDOS PARA A CIRCULAÇÃO, ELIMINANDO EDEMAS, AUMENTANDO O VOLUME SANGUINEO E PROMOVENDO A DIURESE"

E. MEYER - Usos Terapeuticos das Injeções Endovenosas de Soluções de Glucose) Zentralb. f. klin., Med. 102.343, 1925. Abst. J. A. M. A. 86.52I, 1926. 